\title{
Use of Terbium Doped Phosphate Glasses for High Dose Radiation Dosimetry-Thermoluminescence Characteristics, Dose Response and Optimization of Readout Method
}

\author{
Andrzej Gasiorowski ${ }^{1, *(\mathbb{D}}$, Piotr Szajerski ${ }^{1}$ and Jose Francisco Benavente Cuevas ${ }^{2}$ \\ 1 Institute of Applied Radiation Chemistry, Lodz University of Technology, Wroblewskiego 15, \\ 93-590 Lodz, Poland; piotr.szajerski@p.lodz.pl \\ 2 The Center for Energy, Environmental and Technological Research (CIEMAT), Av. Complutense 40, \\ 28040 Madrid, Spain; jf.benavente@ciemat.es \\ * Correspondence: andrzej.gasiorowski@dokt.p.lodz.pl; Tel.: +48-42-631-3073
}

check for updates

Citation: Gasiorowski, A.; Szajerski, P.; Cuevas, J.F.B. Use of Terbium Doped Phosphate Glasses for High Dose Radiation DosimetryThermoluminescence Characteristics, Dose Response and Optimization of Readout Method. Appl. Sci. 2021, 11, 7221. https://doi.org/10.3390/ app11167221

Academic Editors:

Dorota Swiatla-Wojcik,

Yosuke Katsumura and Radosław A. Wach

Received: 3 July 2021

Accepted: 2 August 2021

Published: 5 August 2021

Publisher's Note: MDPI stays neutral with regard to jurisdictional claims in published maps and institutional affiliations.

Copyright: (c) 2021 by the authors. Licensee MDPI, Basel, Switzerland. This article is an open access article distributed under the terms and conditions of the Creative Commons Attribution (CC BY) license (https:// creativecommons.org/licenses/by/ $4.0 /)$.

\begin{abstract}
The phosphate glass samples doped with $\mathrm{Tb}_{2} \mathrm{O}_{3}$ oxide (general formula: $\mathrm{P}_{2} \mathrm{O}_{5}-\mathrm{Al}_{2} \mathrm{O}_{3}$ $\mathrm{Na}_{2} \mathrm{O}-\mathrm{Tb}_{2} \mathrm{O}_{3}$ ) were synthesized and studied for usage in high-dose radiation dosimetry (for example, in high-activity nuclear waste disposals). The influence of terbium concentration on thermoluminescent (TL) signals was analyzed. TL properties of glasses were investigated using various experimental techniques such as direct measurements of TL response vs. radiation dose, $\mathrm{T}_{\max }-\mathrm{T}_{\text {stop }}$ and VHR (various heating rate) methods, and glow curve deconvolution analysis. The thermoluminescence dosimetry (TLD) technique was used as the main investigation tool to study detectors' dose responses. It has been proved that increasing the concentration of terbium oxide in glass matrices significantly increases the thermoluminescence yield of examined material. For the highest dose range (up to $35 \mathrm{kGy}$ ), the dependence of the integrated thermoluminescent signals vs. dose can be considered as a saturation-type curve. Additional preheating of samples improves linearity of signal vs. dose dependencies and leads to a decrease of the signal loss over time. All obtained data suggest that investigated material can be used in high-dose radiation dosimetry. Additional advantages of the investigated dosimetric system are its potential ability to re-use the same dosimeters multiple times and the fact that reading dosimeters only requires usage of a basic TL reader without any modifications.
\end{abstract}

Keywords: dosimetry; ionizing radiation; thermoluminescence; dosimeter; glass; phosphate; terbium

\section{Introduction}

Fast progress and rising interest in technologies involving interactions of ionizing radiation with matter force the continuous development of dosimetric techniques. The number of dosimetric systems present nowadays on the market is limited, especially in the narrow field of high-dose radiation dosimetry (especially in dose ranges up to $35 \mathrm{kGy}$ ). Many of these systems are based on organic compounds and polymers (alanine, poly-methylmethacrylate, etc.) and have numerous limitations in terms of use in harsh environments. One of the potential alternatives that may turn out to be complementary to existing systems is phosphate glasses doped with terbium ions.

Terbium is a lanthanide, belonging to the rare-earth elements (REE) group. REE include lanthanum and the f-block elements, cerium through lutetium. Next to the above, scandium and yttrium are included in this group as well, due to the similar ionic radii with the lighter f-block elements. Moreover, they co-exist together in the same types of ores [1]. Lanthanides exhibit an important feature, namely, they can play the role of light-emitting activators in various matrices. The rare earth phosphors can be divided into two groups: the broad-band-emitting, owing to the $5 \mathrm{~d} \rightarrow 4 \mathrm{f}$ transition $\left(\mathrm{Eu}^{2+}, \mathrm{Ce}^{3+}\right)$, and the narrow-bandemitting, owing to the transition between the $4 \mathrm{f}$ levels like $\mathrm{Tb}^{3+}$. Terbium ion emits green light due to the four sharp peaks arising from ${ }^{5} \mathrm{D}_{4} \rightarrow{ }^{7} \mathrm{~F}_{\mathrm{J}}$ transitions, where $\mathrm{J}=3,4$, or 6 , 
with the strongest emission peak at $550 \mathrm{~nm}[2,3]$. Terbium possesses only one stable isotope $\mathrm{Tb}-159$, characterized by a low nuclear spin value $(\mathrm{I}=3 / 2)$, and exhibits a relatively simple hyperfine structure of its electronic levels [4].

Terbium ions $\left(\mathrm{Tb}^{3+}\right)$ are very often used as dopants in order to extend luminescence properties in various materials, e.g., in nitridosilicates, glasses, and ceramics [5-8]. Terbium ions are also able to play the role of activators in mechano-luminescence light-emission processes, often as inorganic salts such as sulphates, carbonates, nitrates, and chlorides $[9,10]$. Terbium dopants have been also used in various types of thermoluminescent (TL) materials. For example, magnesium orthosilicate doped with terbium $\left(\mathrm{Mg}_{2} \mathrm{SiO}_{4}: \mathrm{Tb}\right)$ has been investigated in TL dosimetry since 1971, thanks to its high sensitivity and effective atomic number of 11 [11,12]. Unfortunately, TL properties of orthosilicates might be unstable, which are strongly influenced by the preparation method [13]. Another group of lightemitting materials that are based on terbium dopant, improving their TL properties, are ionic crystals, e.g., $\mathrm{CsCl}: \mathrm{Tb}^{3+}$, terbium-doped strontium pyrophosphates $\left(\mathrm{Sr}_{2} \mathrm{P}_{2} \mathrm{O}_{7}: \mathrm{Tb}^{3+}\right)$, potassium bromide crystals, and terbium-doped double fluorides [14-17]. Moreover, the application of terbium oxide as a dopant significantly improved the properties of materials that had been already used in TL dosimetry. A straightforward example of such materials is aluminum oxide doped with terbium and thalium [18]. $\mathrm{Lu}_{2} \mathrm{O}_{3}: \mathrm{Tb}$, $\mathrm{Ta}$ ceramic storage phosphors are also a good example of how the presence of terbium ions can significantly change the thermoluminescence properties of materials; $\mathrm{Tb}$,Ta ceramics show high overall TL intensity [19]. Despite all the advantages of the crystal-based phosphors, they possess drawbacks as well. For TL dosimeters based on crystalline systems, one can observe an increased light-scattering efficiency, due to their limited transparency. A reasonably good alternative for these phosphors might be found among dosimetric systems based on glasses, for example, borosilicate glasses [20]. One such example is zinc-lithium-borate glass doped with terbium. Introduction of terbium into the material results in an increase of TL yield, enhancement of sensitivity of the phosphor, and significant minimization of fading behavior [21]. BaO- $\mathrm{P}_{2} \mathrm{O}_{5}$ glasses are also an interesting example of influence of terbium ions on matrices. The analysis of the TL data of $\mathrm{BaO}-\mathrm{M}_{2} \mathrm{O}_{3}-\mathrm{P}_{2} \mathrm{O}_{5}: \mathrm{Tb}_{2} \mathrm{O}_{3}$ glasses suggests that, comparatively, there are high non-radiative losses in $\mathrm{In}_{2} \mathrm{O}_{3}$ mixed glasses [22]. Another example of the improvement of dosimetric characteristics by the introduction of terbium into glass hosts is terbium-doped $\mathrm{CaO}-\mathrm{Al}_{2} \mathrm{O}_{3}-\mathrm{B}_{2} \mathrm{O}_{3}$ glasses. As in the previous case, dosimeters were found to exhibit good sensitivity and linearity. Sadly, for these materials one can observe more than a $60 \%$ decrease in signal intensity in the first $72 \mathrm{~h}$ after irradiation [23].

Phosphate glasses are currently used in various fields of science, technology, and medicine, such as in matrices for high-level radioactive waste (HLW) immobilization, in fast ion conductors, and in bone transplantation [24-26]. Phosphate glasses exhibit lower transition temperatures, lower viscosity when in a molten state, higher thermal expansion coefficients, and higher electrical conductivity than borate and silicate glasses [26]. As shown before, phosphate glasses also possess interesting TL properties suitable for highdose ionizing radiation dosimetry [27]. Glasses doped with $\mathrm{Tb}^{3+}$ are also used in other luminescent materials, for example, lasers. [28]. An obvious advantage of phosphate glass systems is that their synthesis requires significantly lower temperatures and less energy, which makes the process of their preparation economically competitive in comparison with other glasses. In the past, there were some papers dealing with the thermoluminescence of phosphate glasses doped with rare earth elements such as terbium, but none of them investigated in detail thermoluminescence kinetics and the usage of this material in highdose dosimetry [29,30].

The presented work reports the influence of terbium doping on dosimetric properties of phosphate glass by means of thermoluminescence techniques. Here, one investigated the influence of terbium concentration on TL signal characteristics and the dependencies of TL signal intensity vs. dose absorbed in a material. Next to the above, the nature of thermoluminescence signals was investigated using various methods (such as the $\mathrm{T}_{\max }-$ 
$\mathrm{T}_{\text {stop }}$ or VHR methods). Moreover, the paper also proposes the readout method optimal for investigated dosimeters and investigates its influence on TL signals, linearity of signals intensity vs. radiation dose absorbed within the material, and TL signal loss over time.

\section{Materials and Methods}

\subsection{Glass Samples Synthesis}

The phosphate glass samples were synthesized according to the melt-quench technique from raw materials, such as $\mathrm{Na}_{2} \mathrm{CO}_{3}, \mathrm{NH}_{4} \mathrm{H}_{2} \mathrm{PO}_{4}, \mathrm{Al}_{2} \mathrm{O}_{3}$, and $\mathrm{Tb}_{4} \mathrm{O}_{7}$ of highest available purity. The details on the synthesis procedure were discussed in previous papers [27]. Four different glass compositions were prepared for this research. The chemical compositions of each investigated glass system synthesized differed only due to terbium oxide concentration, whereas the main components of the glasses remained practically unchanged. In order to follow the overall influence of the terbium dopant on TL properties of the investigated glasses, for comparison raw (undoped) glass sample was prepared simultaneously (PPG) and investigated in the same manner as terbium-doped glass samples. The detailed compositions of all investigated phosphate glass samples are presented in Table 1.

Table 1. Compositions of raw and terbium-doped phosphate glasses, in weight (mole) \%.

\begin{tabular}{ccccc}
\hline \multirow{2}{*}{ Sample } & \multicolumn{4}{c}{ Composition of Phosphate Glass Samples, in Weight (Mole) $\%$} \\
\cline { 2 - 5 } & $\mathbf{P}_{\mathbf{2}} \mathbf{O}_{\mathbf{5}}$ & $\mathbf{A l}_{\mathbf{2}} \mathbf{O}_{\mathbf{3}}$ & $\mathbf{N a}_{\mathbf{2}} \mathbf{O}$ & $\mathbf{T b}_{\mathbf{2}} \mathbf{O}_{\mathbf{3}}$ \\
\hline PPG & $56.00(38.36)$ & $12.00(11.44)$ & $32.00(50.20)$ & - \\
PPG_Tb01 & $55.94(38.34)$ & $11.99(11.44)$ & $31.97(50.19)$ & $0.10(0.03)$ \\
PPG_Tb05 & $55.72(38.31)$ & $11.94(11.43)$ & $31.84(50.13)$ & $0.50(0.13)$ \\
PPG_Tb30 & $54.03(38.07)$ & $11.54(11.32)$ & $30.85(49.79)$ & $3.00(0.82)$ \\
\hline
\end{tabular}

The as-synthesized glass was grounded in a planetary ball mill (Retsch PM100, Haan, Germany) using zirconium oxide $\left(\mathrm{ZrO}_{2}\right)$ grinding vessel and balls. The obtained powders were classified using laboratory sieves, to remove remaining coarse fraction.

\subsection{XRD and DSC Analysis of Phosphate Glasses}

To confirm the glassy state of the phosphate glass samples XRD (X-Ray Diffraction), analysis was performed using powdered samples. The X-ray diffractometer used was X'Pert Pro MPD (PANanalytical, Almelo, The Netherlands), and measurements were performed within 2theta angle between 5-60 deg. Data acquisition was carried out using $\mathrm{Cu} \mathrm{K} \alpha$ radiation and scan rate of $6 \mathrm{deg} / \mathrm{min}$, whereas X-ray tube was operating at $40 \mathrm{kV}$ and $30 \mathrm{~mA}$. Next to XRD analysis, one also performed differential scanning calorimetry analysis of the native and terbium-doped phosphate glasses within $40-550{ }^{\circ} \mathrm{C}$ temperature range using Q200 DSC (TA Instruments, New Castle, DE, USA) with ca. $15 \mathrm{mg}$ samples in aluminum crucibles applying a heating rate of $20 \mathrm{deg} / \mathrm{min}$.

\subsection{Preparation of Glass Pellet Dosimeters}

To enhance properties of detectors and to facilitate manual operations, powders of phosphate glass were pressed into pellets. The weighted portions of glass powders $(40 \mathrm{mg})$ were placed in the cylindrical pressing die (hole diameter: $5 \mathrm{~mm}$ ). Materials were compressed using a hydraulic press, then pellets were sintered in a laboratory furnace (LE6/11/P300, Nabertherm, Lilienthal, Germany) for $1 \mathrm{~h}$ at $420^{\circ} \mathrm{C}$. The sintering step was applied to improve the mechanical properties of the detectors and to erase any residual TL signals from the detectors.

\subsection{Samples Irradiation}

The investigated samples were irradiated using $\gamma$ and $\beta$ radiation installed in Institute of Applied Radiation Chemistry, Lodz University of Technology. Gamma irradiation was performed using Co-60 radiation source installed in Ob-Servo-D panoramic irradiator 
(Izotop, Budapest, Hungary), whereas $\beta$ - irradiation was performed using electron beam from linear electron accelerator (ELU-6E), which was able to produce electrons of energy of $6 \mathrm{MeV}$. The e-beam irradiation was performed in a single-pulse mode (17 ns or $4 \mu \mathrm{s}$ duration), depending on the required dose. The range of cumulative doses applied to samples using $17 \mathrm{~ns}$ pulses was $0.06-1.0 \mathrm{kGy}$ and $0.33-35 \mathrm{kGy}$ for $4 \mu \mathrm{s}$ pulses. As a reference, for verification of radiation dose delivered to the samples, e-Scan alanine dosimetry system (Bruker, Karlsruhe, Germany) was used.

\subsection{Thermoluminescence (TL) Measurements}

TLD reader (Mikrolab TL Ra94, Poland) was used for thermoluminescence emission measurements. The measurements were carried out in the analyzer mode, within the temperature range of $40-400{ }^{\circ} \mathrm{C}$ using heating rate of $5 \mathrm{deg} / \mathrm{s}$. Due to excessive light emission from samples containing terbium, it was necessary to use a shutter with hole (diameter of $0.5 \mathrm{~mm}$ ) to limit light flux reaching photomultiplier tube.

To estimate influence of the shutter used on thermoluminescence signal integrals, additional experiment was performed. Commercially available LiF dosimeters (MCP-N) were irradiated with different doses and read out with and without shutter. The slopes of the functions integrals vs. dose were calculated. Ratio of slopes between these two reading conditions determined the ability of the shutter to reduce light. For the shutter used, TL signal intensity was reduced by two orders of magnitude. Due to much lower light-emission intensity in case of undoped (raw) phosphate glass, the shutter was not used.

\section{Results}

\subsection{Results of XRD and DSC Analysis of Synthesized Glasses}

All synthesized samples were analyzed using X-ray powder diffraction technique to ensure their glassy state. As one can see from the diffraction patterns presented in Figure 1a, one should consider all phosphate glass samples as fully amorphous materials. The lack of crystalline peaks is observed for all samples, even for PPG_Tb30 sample, containing relatively high contribution $(3.0 \%, w / w)$ of $\mathrm{Tb}_{2} \mathrm{O}_{3}$ oxide. The presented XRD patterns show that for all samples only wide scattering peaks (so called "halo") are observed at ca. $21^{\circ}$ and $31^{\circ} 2$ theta angles. In the low range of 2 theta angle $\left(5^{\circ}\right.$ to $\left.16^{\circ}\right)$, one can also observe an increased background intensity due to more efficient X-ray scattering in air. Obtained X-ray patterns are similar to those that can be find in literature [31-33]. The results of DSC analysis are presented in Figure 1b. Thermal analyses were carried out within the temperature range of $40-550{ }^{\circ} \mathrm{C}$ and confirmed the glassy nature of the investigated materials by existing of the glass transitions within the temperature range of $407-423^{\circ} \mathrm{C}$. For pure, undoped phosphate glass, the glass transition temperature was determined at $423{ }^{\circ} \mathrm{C}$, whereas for the terbiumdoped samples the transition temperatures were shifted towards lower values between $408-410{ }^{\circ} \mathrm{C}$. In terms of DSC, for undoped phosphate glass exhibits there was similar $\mathrm{T}_{\mathrm{g}}$ to that reported in literature [34]. Decreasing of $\mathrm{T}_{\mathrm{g}}$ temperature for terbium-doped glasses may be caused by a global weakening of the glass network induced by relatively large $\mathrm{Tb}^{3+}$ ion incorporation, which can be ascribed to the increase in non-bridging oxygens due to the cleavage of $\mathrm{P}-\mathrm{O}-\mathrm{P}$ bonds to form $\mathrm{P}-\mathrm{O}-\mathrm{Tb}^{2+}[35-38]$. However, this issue requires further research using other research methods, for example, NMR. 

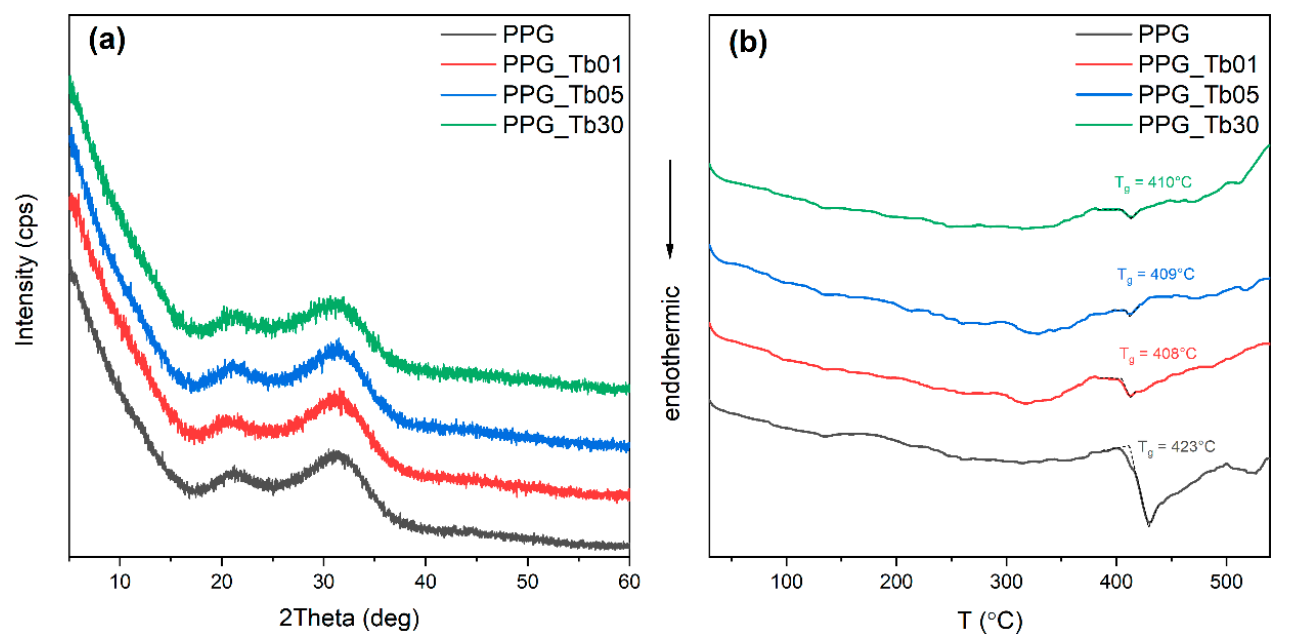

Figure 1. XRD patterns (a) and DSC traces (b) of synthesized phosphate glasses.

\subsection{Thermoluminescence (TL) Characteristics of Irradiated Glasses}

The phosphate glass dosimeters samples were irradiated in different modes in order to investigate the detectors response. For this purpose, both electron beam and gamma photon irradiation were performed on investigated samples.

\subsubsection{Electron Accelerator, Pulse Duration $4 \mu \mathrm{s}$}

At first, the native (undoped) and terbium-doped phosphate glass samples were irradiated using electron accelerator with pulse duration of $4 \mu \mathrm{s}$. The range of radiation doses delivered to the samples was 1-30 kGy. The results of these experiments are depicted in Figure 2, where TL glow curves for each sample is presented for different radiation doses. The undoped phosphate glass already exhibits thermoluminescent properties. The irradiated samples of PPG glass show wide, complex TL signals with maximum emission at ca. $125{ }^{\circ} \mathrm{C}$ (cf. Figure 2a). For the higher radiation doses, it is also possible to identify higher temperature peak, which in TL curves is located at ca. $180^{\circ} \mathrm{C}$ (Figure 2a). For all terbiumdoped samples, special shutter was installed to decrease amount of light reaching PMT tube (ca. 100 times). As one can see in Figure 2b, $0.1 \%$ addition of terbium oxide increases the yield of thermoluminescence significantly in comparison with native phosphate glass. Higher contribution of terbium results in further increasing of TL intensity, which can be clearly observed in Figure $2 \mathrm{c}, \mathrm{d}$. For the glass samples doped with $0.5 \%$ of terbium oxide, the maximum of signals appears at ca. $225^{\circ} \mathrm{C}$ (Figure $2 \mathrm{~b}, \mathrm{c}$ ). Further increasing of terbium concentration in glass, to $3 \%$, is followed by formation of additional signal at higher temperatures. This is clearly presented in Figure $2 \mathrm{~d}$, where one can observe low temperature signal at ca. $125^{\circ} \mathrm{C}$ with easily recognized signal at $275^{\circ} \mathrm{C}$. Signal at $125^{\circ} \mathrm{C}$ is common for all samples irradiated with different doses, whereas peak at $275^{\circ} \mathrm{C}$ appears for radiation doses higher than $8 \mathrm{kGy}$. Moreover, for radiation dose of $31 \mathrm{kGy}$ one can observed partial degradation of the low temperature signal. Additionally PPG_Tb01and PPG_Tb30 shows an extensive change in the peak positions at higher radiation dose than in PPG_Tb05. Such effect may be due to the intensity of glass network modification process caused by introduction of terbium dopant. In case of low content of terbium, one deals only with slight modification of the glass network, whereas when increasing terbium oxide concentration one can expect more significant change of glass matrix structure and weakening of the glass-network-forming bonds. Such processes may lead to formation of additional trap centers, which can be more easily bleached when irradiated with higher doses. For the presented glow curves, one can also observe the slight distortions of the signal shape related to the increasing radiation dose. Nevertheless, the overall character of the presented glow curves remains similar for each glass sample. This effect may be related to the possible thermal and geometrical conditions during readout and/or imperfect grain 
size distribution of the material used for detectors preparation, which was already observed previously [39]. As one can see in Figure 2, introduction of terbium ions into the glass matrix significantly modifies thermoluminescence signals, both in terms of their shapes and intensity. Thermoluminescence signals at 125 and $180^{\circ} \mathrm{C}$ may have their origins from pure glass lattice. For doped glasses, one can observe additional signals at 225 and $275{ }^{\circ} \mathrm{C}$ that are clearly caused by presence of $\mathrm{Tb}$. The more detailed explanation for these effects is presumably related to the facts - that aluminophosphate glasses contain $\mathrm{PO}_{4}$ tetrahedra as well as $\mathrm{AlO}_{4}$ units, which are able to induce point defects owing to the fact of mismatching in bonding as well as formation links with neighboring phosphorous elements. Due to the presence of point defects, the simultaneous occurrence of localized energy levels within the band gap is possible [40].
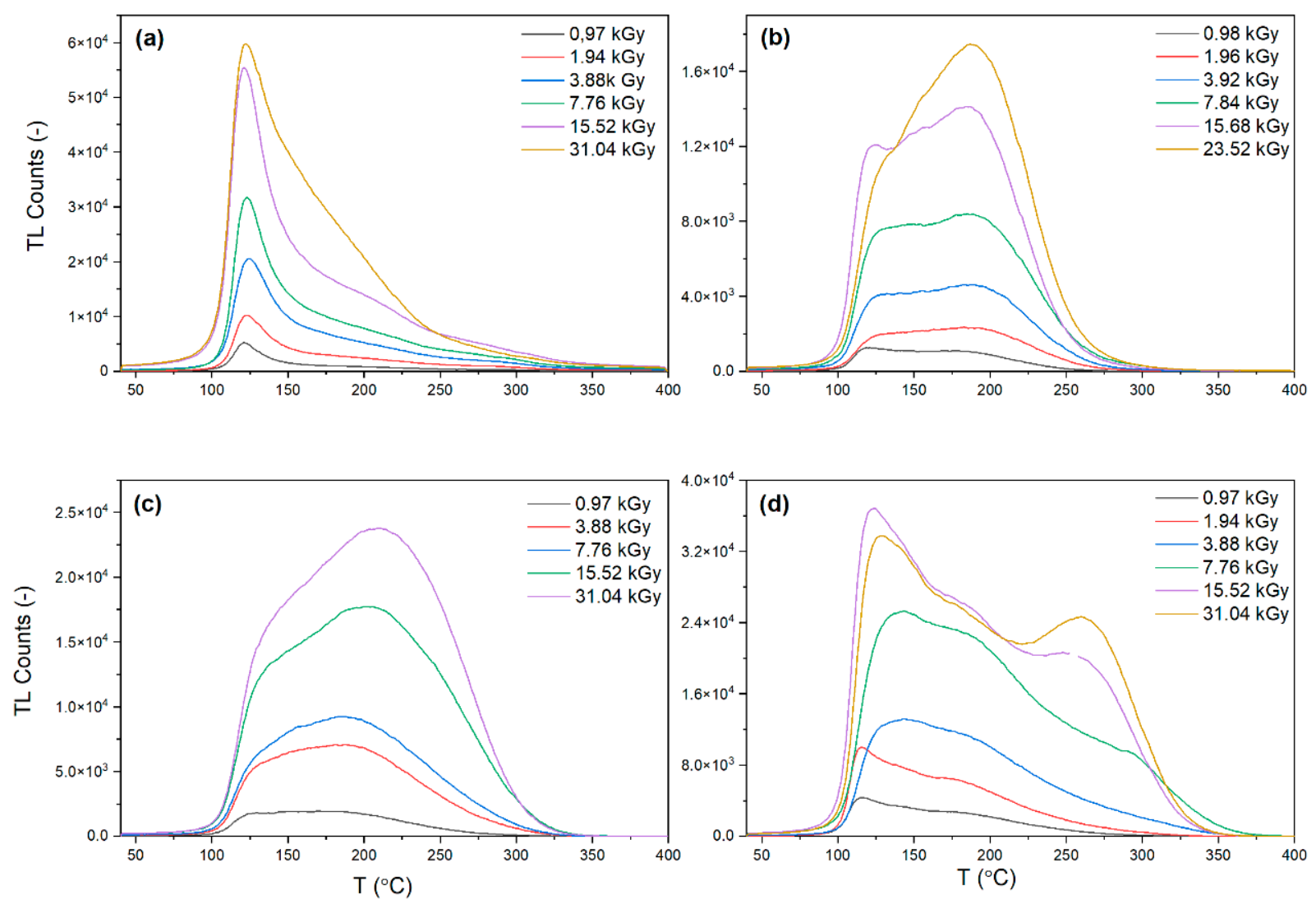

Figure 2. TL curves for samples irradiated using beta radiation (4 $\mu$ s pulse duration), PPG (a), PPG_Tb01 (b), PPG_Tb05, (c) and PPG_Tb30 (d). PPG samples were read without shutter.

Rare earth metals, such as terbium, induce higher sensitivity in TL materials [21]. From literature it is known that matrix distortions due to presence of large dopant ions such as $\mathrm{Tb}^{3+}$ may form complex defect sites, which can be stabilized by $\mathrm{Na}^{+}$and intrinsic oxygen vacancies [41]. The possible mechanism of TL emission from terbium-doped phosphors includes few steps. It is considered that trivalent terbium ions $\mathrm{Tb}^{3+}$ may be effectively reduced by free electrons formed in the matrix after $\beta$ - and $\gamma$ irradiation. Further, the formed $\mathrm{Tb}^{2+}$ ion is efficient hole scavenger, forming excited $\mathrm{Tb}^{3+}$ ions in this process, and TL emission is considered to follow the reaction expressed by Equation (1).

$$
\mathrm{Tb}^{2+}+\text { hole } \rightarrow \mathrm{Tb}^{3+*} \rightarrow \mathrm{Tb}^{3}+\lambda v
$$

The holes are supplied by traps via thermal excitation [42]. An elegant explanation for these mechanisms based on the simultaneous participation of rare earth metals ions and interstitial oxygen atoms is presented in the Abdel-Kader paper [43]. The complex 
nature of energy transitions between excited states and ground level of Tb3+ ions involves different transitions between $\mathrm{D}$ and $\mathrm{F}$ levels (especially ${ }^{5} \mathrm{D}_{4} \rightarrow{ }^{7} \mathrm{~F}_{6},{ }^{5} \mathrm{D}_{4} \rightarrow{ }^{7} \mathrm{~F}_{5},{ }^{5} \mathrm{D}_{4} \rightarrow{ }^{7} \mathrm{~F}_{4}$ and ${ }^{5} \mathrm{D}_{4} \rightarrow{ }^{7} \mathrm{~F}_{3}$ ), which are then responsible for enhanced photon emission from terbium-doped materials [44].

As one can see in Figure 3, dependencies of signal integral vs. dose cannot be considered as linear and are clearly saturation-type curves, which resemble functions of exponential type. The integrated luminescence intensity $\left(\mathrm{N}_{\mathrm{int}}\right)$ may be approximated by a simple summation, according to Equation (2) [39]:

$$
\mathrm{N}_{\text {int }}=\int_{\mathrm{T}_{0}}^{\mathrm{T}} \mathrm{N}_{\mathrm{p}}(\mathrm{T}) \mathrm{dT}=\sum_{\mathrm{T}_{0}}^{\mathrm{T}} \mathrm{N}_{\mathrm{p}}(\mathrm{T})
$$

where $\mathrm{Np}$ is the photon count intensity at point temperature $\mathrm{T}$. For the approximation of the experimental data presented in Figure 2, the function expressed by Equation (3) can be used:

$$
\mathrm{N}_{\text {int }}=\mathrm{N}_{\mathrm{inf}}\left(1-\mathrm{e}^{-\mathrm{kD}}\right)
$$

where $\mathrm{N}_{\text {inf }}$ is the pre-exponential factor dependent on the material properties and related to the saturation intensity, $\mathrm{k}$ is the thermoluminescence yield per unit dose factor or material sensitivity coefficient, in kGy-1, and D is the radiation dose in kGy. It is obvious that increasing the $\mathrm{Tb}^{3+}$ ions concentration has the most pronounced influence on the lightemission efficiency, what is also confirmed by the data provided in the further parts of this work. The sensitizing effect of rare earth elements was already discussed in previous papers, where other glass samples containing such types of dopants were investigated [27,45-47]. It seems that terbium is one of the most efficient sensitizing agent among rare earth metals. However, for the terbium ions the strongest enhancement of the light-emission efficiency is observed for the low dopant concentration range to upmost few percent and decrease above this value. Above relatively low concentrations of ca. $0.3 \%$, one observed the quenching effects due to simultaneous effects of multipolar transitions or these related to the so called inner effect filter, which were observed already for terbium concentration starting from 6 (mole) \% [46,47]. The data obtained and presented in this study correlate well with those provided in literature, which is demonstrated by the results provided in Figure 3, such as the significant increase of TL intensity when shifting from PPG_Tb01 sample to PPG_Tb05 and lower efficiency for further transition to PPG_Tb30 glass.

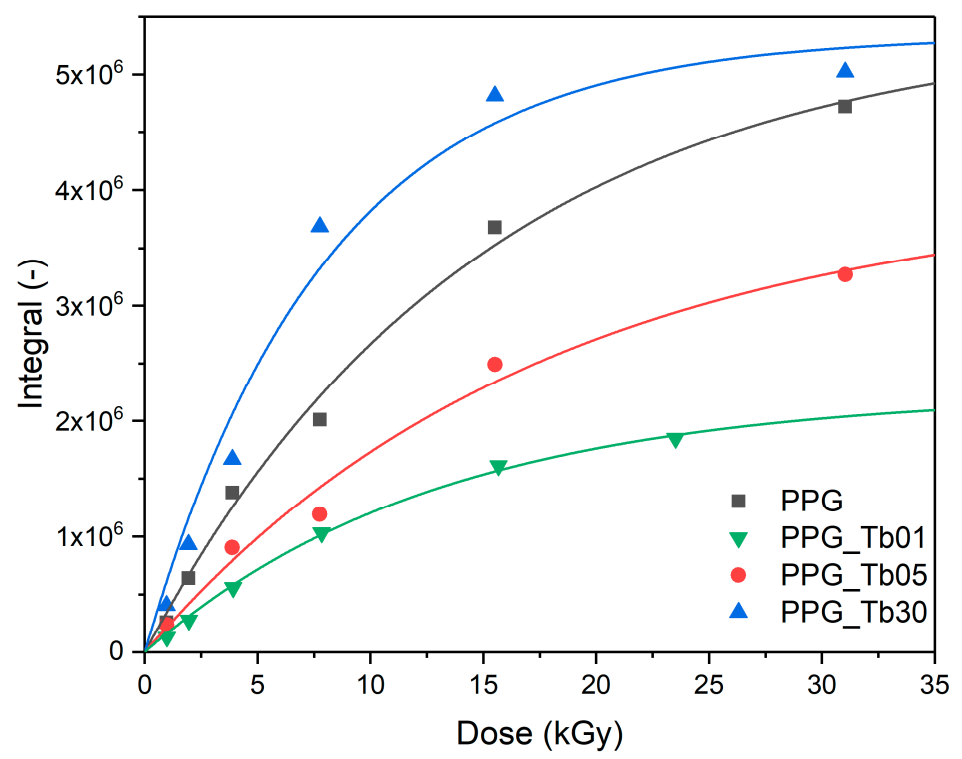

Figure 3. Dependencies of TL signal integral vs. dose absorbed for glass dosimeter irradiated with beta radiation $(4 \mu \mathrm{s})$; for PPG sample, TL glow curves were recorded without shutter. 
Considering samples containing terbium, one can observe that with increasing amount of $\mathrm{Tb}_{2} \mathrm{O}_{3}$ in the glass, the yield of luminescence increases. As can be found from data included in Table 2, despite the shutter, samples of terbium-doped glass possess similar or even higher coefficients than undoped glass that was read without shutter, with observable tendency to increase with the terbium concentration (except of $k$ coefficient value for the sample PPG_Tb01).

Table 2. Parameters of fitted linear functions for glass samples (dose 1-30 kGy).

\begin{tabular}{ccccc}
\hline & PPG & PPG_Tb01 & PPG_Tb05 & PPG_Tb30 \\
\hline $\mathrm{N}_{\text {inf }}$ & $(5.4 \pm 0.3) \times 10^{6}$ & $(2.3 \pm 1.0) \times 10^{6}$ & $(4.0 \pm 0.5) \times 10^{6}$ & $(5.3 \pm 0.4) \times 10^{6}$ \\
$\mathrm{k}$ & $(6.7 \pm 0.8) \times 10^{-2}$ & $(7.7 \pm 0.6) \times 10^{-2}$ & $(5.7 \pm 1.3) \times 10^{-2}$ & $(12.0 \pm 2.0) \times 10^{-2}$ \\
Adj. R-Square & 0.992 & 0.997 & 0.980 & 0.971 \\
\hline
\end{tabular}

\subsubsection{Electron Accelerator, Pulse Duration $17 \mathrm{~ns}$}

For verification of the behavior of the investigated glasses for the lower dose ranges, samples were irradiated with radiation doses up to 1000 Gy. During this experiment, samples were irradiated by electron accelerator with pulse duration of $17 \mathrm{~ns}$.

As shown in Figure 4a, the raw phosphate glass possesses maximum of TL signal at $125^{\circ} \mathrm{C}$. For radiation dose of ca. $2 \mathrm{kGy}$, one can easily find additional maximum, which appears at ca. $210^{\circ} \mathrm{C}$; however, after closer analysis this signal is also observable for the lower doses. For the glass samples containing terbium (Figure $4 \mathrm{~b}-\mathrm{d}$ ), one can observe wide TL signals from 100 to $250^{\circ} \mathrm{C}$, whose shapes suggest more complex structure. Probably next to the main signals at $125^{\circ} \mathrm{C}$ (signal from glass matrix) and at $200^{\circ} \mathrm{C}$, other TL peaks also contribute to the overall emission from terbium-doped glass. This will be further discussed in Section 3.3.
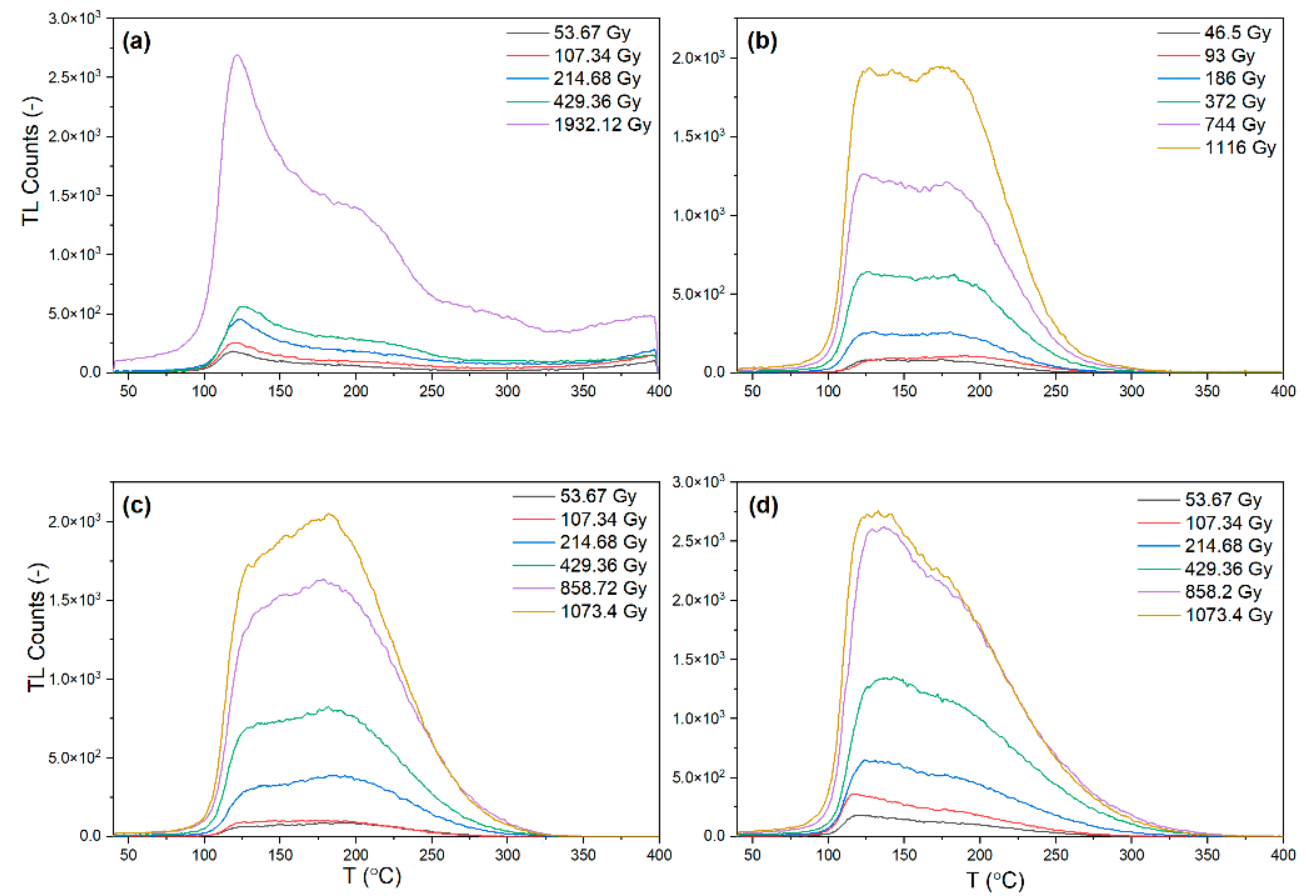

Figure 4. TL curves for samples irradiated using beta radiation (17 ns pulse duration), PPG (a), PPG_Tb01 (b), PPG_Tb05 (c), and PPG_Tb30 (d). PPG samples were read without shutter.

As one can see in Figure 5, all samples exhibit linear dependencies of TL signal intensity vs. dose in the dose range from 50 to 2000 Gy. Analyzing data included in Table 3, one can see that yield of TL emission is directly linked with amount of dopant in the glass, analogical as in case of higher dose ranges, for which the results were presented 
in Section 3.2.1. With increasing concentration of rare earth oxide, the total TL emission increases significantly.

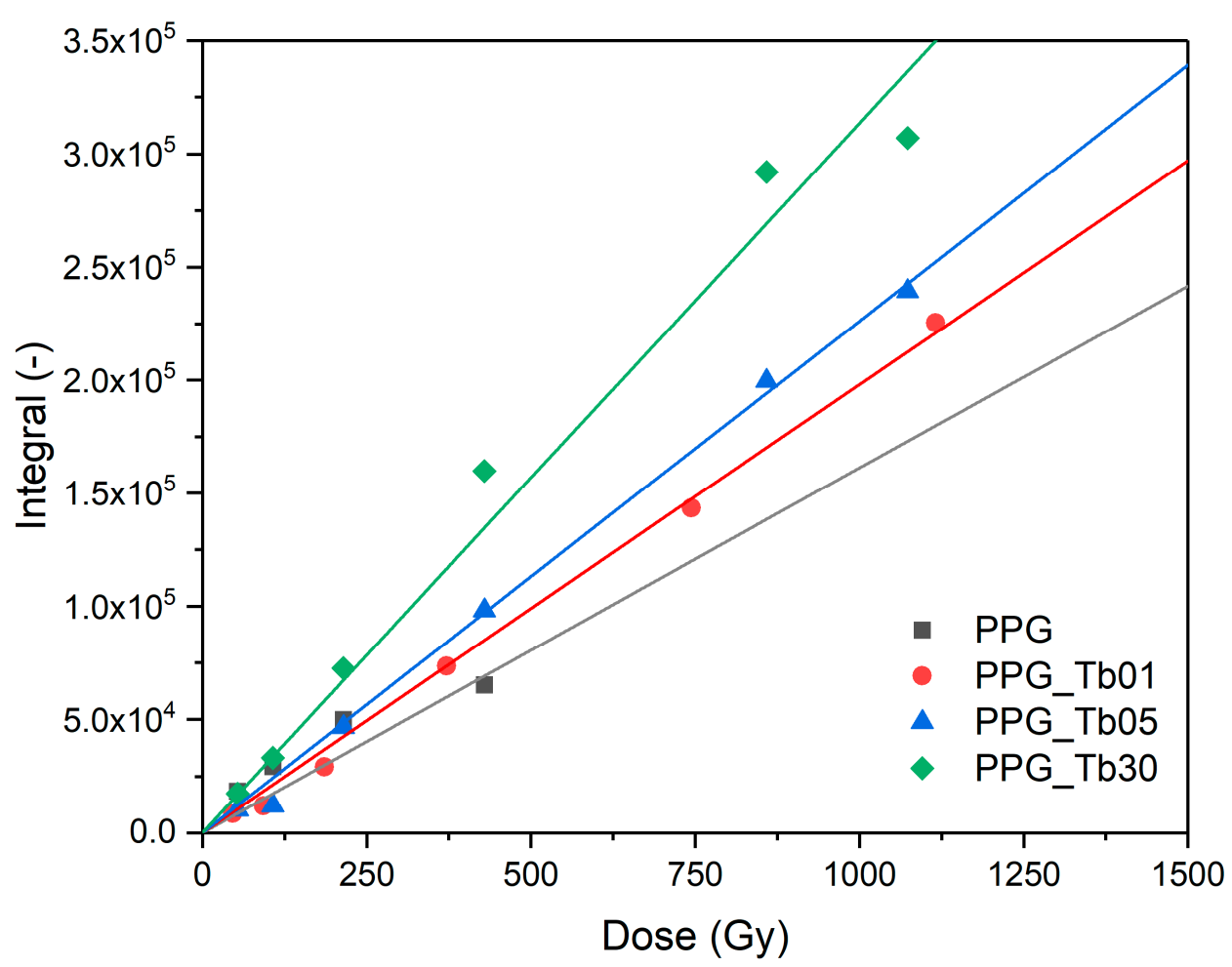

Figure 5. Dependencies of TL signal integral vs. dose absorbed for glass dosimeter irradiated with beta radiation (17ns); for PPG sample, TL glow curves were recorded without shutter.

Table 3. Parameters of fitted linear functions for glass samples (radiation dose 50-2000 Gy).

\begin{tabular}{ccccc}
\hline & PPG & PPG_Tb01 & PPG_Tb05 & PPG_Tb30 \\
\hline Slope & $(1.6 \pm 0.1) \times 10^{2}$ & $(2.0 \pm 0.1) \times 10^{2}$ & $2.3 \pm 0.1) \times 10^{2}$ & $(3.1 \pm 0.1) \times 10^{2}$ \\
Pearson's r & 0.998 & 0.999 & 0.999 & 0.995 \\
\hline
\end{tabular}

\subsubsection{Radiation Chamber, Gamma Irradiation (1.5-7.5 kGy)}

Gamma irradiation was performed using Co-60 source (Ob-Servo-D panoramic irradiator). The samples were placed on sources housing surrounding Co-60 radiation sources.

As one can see in Figure 6a, raw phosphate glass possesses maximum of TL signal at $140{ }^{\circ} \mathrm{C}$, that is, at temperature of ca. $15^{\circ} \mathrm{C}$ higher in comparison with electron beam irradiated samples. Additional peaks appear at $210^{\circ} \mathrm{C}$ and $280^{\circ} \mathrm{C}$. For samples containing terbium (Figure $6 \mathrm{~b}-\mathrm{d}$ ), one can observe a wide TL complex signal from 100 to $300^{\circ} \mathrm{C}$. For samples containing $3 \%$ of terbium oxide, additional maximum at $300{ }^{\circ} \mathrm{C}$ is observed for doses above $5 \mathrm{kGy}$. Comparing the data provided in Figures 4 and 6, one can easily find that native PPG glasses exhibit weak or moderate light-emission ability, whereas it is not observed for the terbium-doped samples. Taking this observation under analysis, it is possible to explain such behavior by two effects. On one hand, the PPG glasses were measured without light reducing shutter, due to significantly lower light-emission efficiency as compared to $\mathrm{Tb}^{3+}$ doped glasses, so even weaker signals may be easily observed, especially for higher radiation doses. On the other hand, as a reasonable explanation for the lack of light emission in case of terbium-doped glasses, it is possible that incorporation of the $\mathrm{Tb}^{3+}$ ions into glass matrix modifies the trap structure in such a way that deep traps existing in native PPG glass are converted into traps, which are emptied almost completely at lower temperatures. 

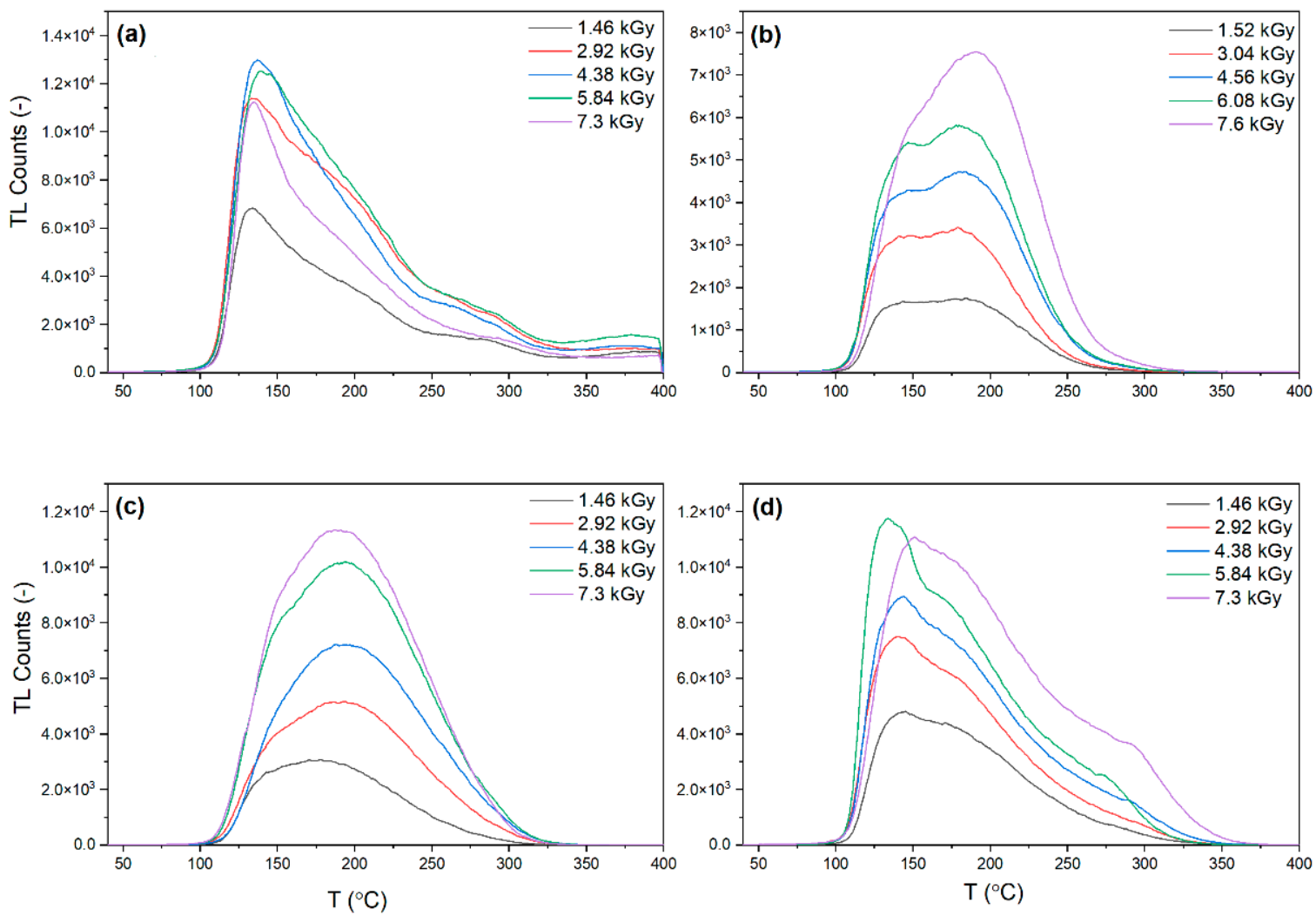

Figure 6. TL curves for samples irradiated using gamma radiation (irradiation chamber), PPG (a), PPG_Tb01 (b), PPG_Tb05 (c), and PPG_Tb30 (d); PPG samples read without shutter.

As can be seen in Figure 7, all samples doped with terbium oxide exhibit close to linear dependencies of TL signal intensity vs. dose in the dose range from 1 to $8 \mathrm{kGy}$. One can see in Table 4 that also for gamma irradiation, yield of TL emission is linked with amount of dopant in glass. For all samples, goodness of function fitting is near 1, except for samples of PPG (undoped) glass-this is probably caused by incorrect position of these kinds of detectors during irradiation.

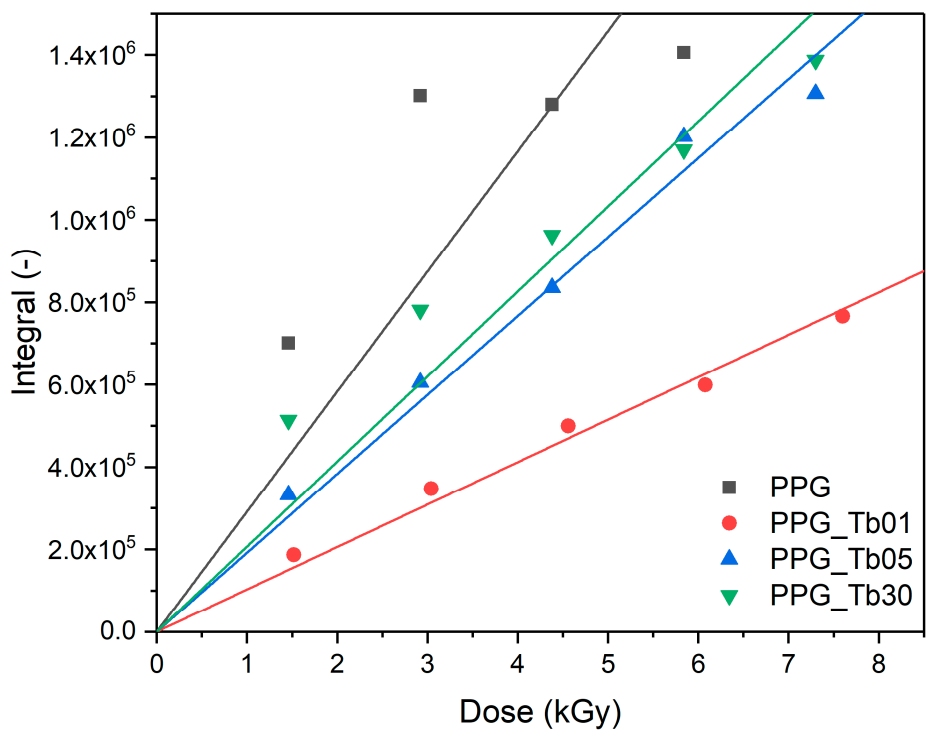

Figure 7. Dependencies of TL signal integral vs. dose absorbed for samples irradiated using gamma radiation (irradiation chamber); for PPG sample, TL glow curves were recorded without shutter. 
Table 4. Parameters of fitted linear functions for glass samples (dose 50-2000 Gy).

\begin{tabular}{ccccc}
\hline & PPG & PPG_Tb01 & PPG_Tb05 & PPG_Tb30 \\
\hline Slope & $(2.9 \pm 0.4) \times 10^{5}$ & $(1.0 \pm 0.3) \times 10^{5}$ & $(1.9 \pm 0.7) \times 10^{5}$ & $(2.1 \pm 0.1) \times 10^{5}$ \\
Pearson's r & 0.968 & 0.998 & 0.998 & 0.99 \\
\hline
\end{tabular}

\subsection{Analysis and Structure of TL Emission from Phosphate Glasses}

As one can find, from the previous data, changing concentration of terbium oxide in phosphate glasses leading to increase of their thermoluminescence yield and also influencing the shapes of TL curves. Because of this, it was necessary to investigate TL mechanism in synthesized glasses. To follow and analyze the impact of terbium dopant and its concentration on TL signal and traps structure, one can apply verified approach based on the mixed experimental methods and computerized deconvolution of the TL curves. The substantial question was the selection of the proper traps distribution model, which should be selected for glow curves deconvolution procedure. Thus, at first one performed $\mathrm{T}_{\max }-\mathrm{T}_{\text {stop }}$ measurements for both pure PPG and terbium-doped glass samples irradiated with $10 \mathrm{kGy}$ radiation dose, within the temperature ranges of $50-360^{\circ} \mathrm{C}$ and changing temperature in $2-6{ }^{\circ} \mathrm{C}$ steps. The results obtained from these experiments are presented in Figure 8. From the presented data, one can easily determine the number and nature of traps present in the investigated glasses. For pure PPG glass sample (Figure 8a), the dependence of position of the first maximum present in a glow curve $\left(T_{\max }\right)$ obtained during reading the sample after irradiation and preheating to $T_{\text {stop }}$ temperature vs. $T_{\text {stop }}$ revealed the existence of five trapping centers. The first peak represented by a flat line in region of $50-90{ }^{\circ} \mathrm{C}$ was characterized as a single first order kinetics (FOK) signal, next three signals were identified as defects with continuous distribution of energy (straight increasing lines in regions $90-140,140-190$, and $190-310^{\circ} \mathrm{C}$ ), whereas the last peak visible as a flat region followed by an increasing tail gave presumption for existence of a single general order kinetics (GOK) peak in the region of $280-360{ }^{\circ} \mathrm{C}$ [48]. Similar analysis of the terbium-doped glass delivered evidence for existence of one FOK peak in the region of $50-90^{\circ} \mathrm{C}$ and five peaks with a continuous trap energy distribution in regions of 90-110, $110-130,130-160,160-190$, and $190-320^{\circ} \mathrm{C}$.
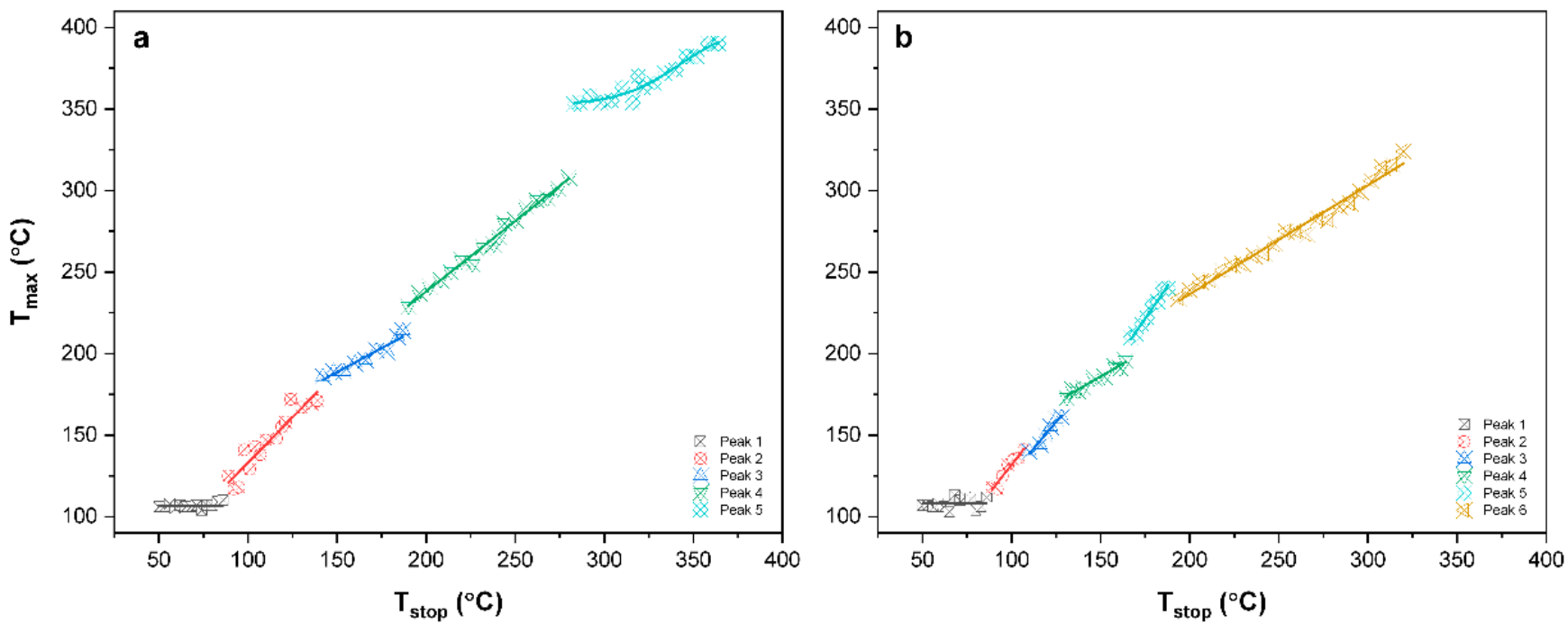

Figure 8. $\mathrm{T}_{\max }-\mathrm{T}_{\text {stop }}$ analysis for pure PPG (a) and terbium-doped (b) glass samples; irradiation dose $10 \mathrm{kGy}$ per point, heating rate $2{ }^{\circ} \mathrm{C} / \mathrm{s}$.

Direct determination of the exact positions of signals contributing to a complex glow curve with strongly overlapping peaks is always a difficult task, so next to the presented 
above $T_{\max }-T_{\text {stop }}$ measurements, one also performed variable heating rate method to facilitate the resolving of the glow curves structure. The method was applied both for pure phosphate glass (PPG) and for terbium-doped samples within the heating rates between $0.5-10{ }^{\circ} \mathrm{C}$ on samples irradiated with $10 \mathrm{kGy}$ radiation dose. Results of these measurements are presented in Figure 9. In case of terbium-doped samples, shutter-reducing light intensity had to be applied. From the VHR measurements, the shifting of TL emission maxima is evident. For PPG sample (cf. Figure 9a), the most prominent peak maximum moves from 98 to $145{ }^{\circ} \mathrm{C}$, upon changing heating rate from 0.5 to $10^{\circ} \mathrm{C} / \mathrm{s}$. Unfortunately, due to the strong overlapping of peaks, this is the only signal whose position may be unambiguously determined. Nevertheless, the overall shapes of the TL emission curves remain similar, regardless of heating rate applied.
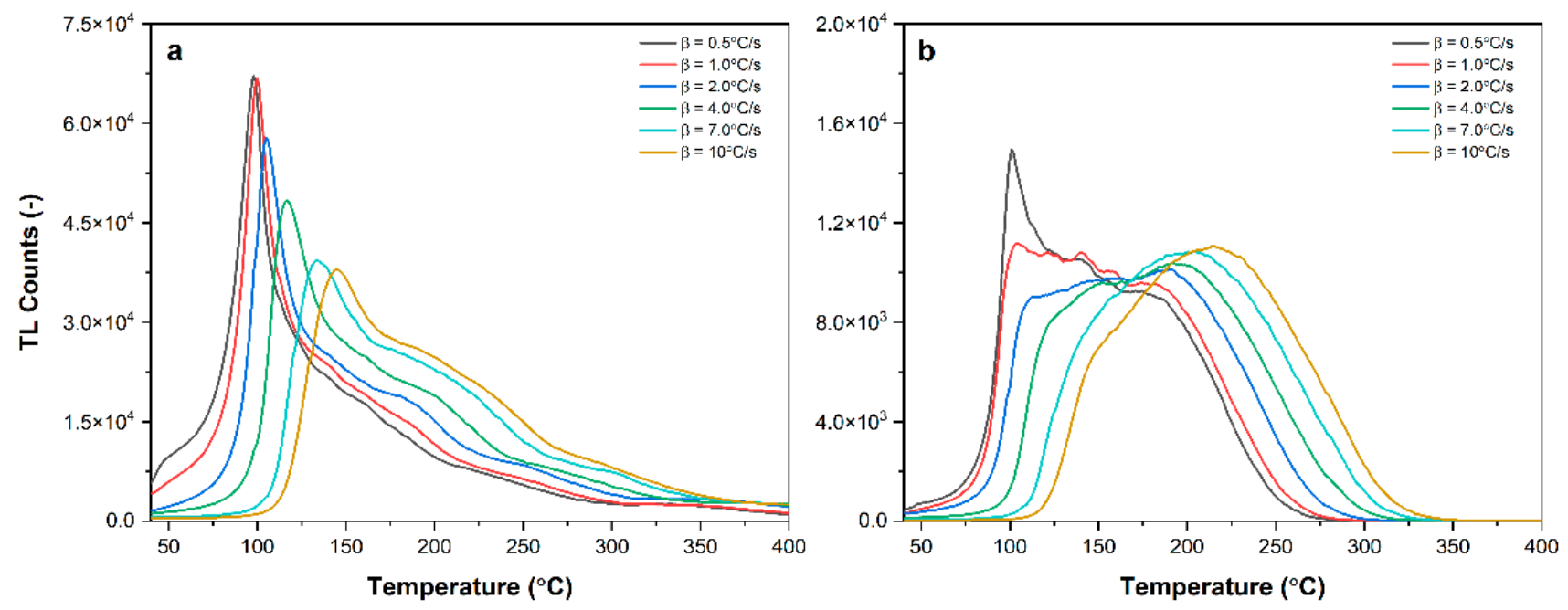

Figure 9. TL glow curves of PPG (a) and terbium-doped phosphate glass (b), PPG_Tb05) measured at various heating rates (irradiation dose ca. $10 \mathrm{kGy}$, terbium-doped glass measured using shutter reducing light intensity ca. $100 \times$ ).

For terbium-doped glass $\left(0.5 \% \mathrm{~Tb}_{2} \mathrm{O}_{3}, \mathrm{PPG}_{-} \mathrm{Tb} 05\right.$, cf. Figure $\left.9 \mathrm{~b}\right)$ and the lowest heating rate of $0.5^{\circ} \mathrm{C} / \mathrm{s}$, one can easily determine the low temperature peak position at $101{ }^{\circ} \mathrm{C} / \mathrm{s}$ and roughly the position of the other, higher temperature peak at ca. $175^{\circ} \mathrm{C}$. Moreover, for terbium-doped glass the much stronger dependence of the overall $\mathrm{TL}$ emission curves vs. heating rate can be easily found. Increasing the heating rate, the intensity of the first peak decreases progressively; however, it can be still easily found even in case of the highest heating rate of $10^{\circ} \mathrm{C} / \mathrm{s}$ on the lower temperature shoulder of the most prominent TL emission peak, whose maximum is located at ca. $200{ }^{\circ} \mathrm{C} / \mathrm{s}$. Very similar results based on the VHR method were observed also for the 0.1 and $3.0 \% \mathrm{~Tb}_{2} \mathrm{O}_{3}$-doped phosphate glasses (PPG_Tb01 and PPG_Tb30).

Due to the significant complexity of the presented TL emissions, it is very difficult to completely analyze the structure of the glow curves and contribution of the particular TL peaks taking into account only results obtained from $\mathrm{T}_{\max }-\mathrm{T}_{\text {stop }}$ and VHR measurements. Nevertheless, they can be a starting point for the deconvolution analysis using specialized software with implemented appropriate TL models. Based on the data presented above, one can propose models suitable for resolving observed TL glow curves. For the PPG glass, the model involves mixed contribution of FOK peak, three continuous energy distribution peaks, and GOK signal, according to Equation (4):

$$
\mathrm{I}_{\mathrm{TL}}(\mathrm{T})=\mathrm{I}_{\text {Peak1 }}^{\mathrm{FOK}}(\mathrm{T})+\mathrm{I}_{\text {Peak2 }}^{\text {Cont }}(\mathrm{T})+\mathrm{I}_{\text {Peak3 }}^{\text {Cont }}(\mathrm{T})+\mathrm{I}_{\text {Peak4 }}^{\text {Cont }}(\mathrm{T})+\mathrm{I}_{\text {Peak5 }}^{\mathrm{GOK}}(\mathrm{T})
$$

where $\mathrm{I}_{\mathrm{TL}}$ and $\mathrm{I}_{\text {Peak (1-5) }}$ are total and fractional TL intensities due to the particular peaks contributions. Such a combined approach to TL glow curve analysis has already been 
applied and reported in literature [49]. The glow peaks following first (FOK) and general order kinetics (GOK) were fitted using Equations (5) and (6) [48,50]:

$$
\begin{gathered}
\mathrm{I}^{\mathrm{FOK}}(\mathrm{T})=\mathrm{I}_{\mathrm{m}} \exp \left(\frac{\mathrm{E}}{\mathrm{kT}}-\frac{\mathrm{E}}{\mathrm{kT}}\right) \exp \left[-\frac{\mathrm{E}}{\mathrm{kT}_{\mathrm{m}}^{2}} \int_{\mathrm{T}_{m}}^{\mathrm{T}} \exp \left(\frac{\mathrm{E}}{\mathrm{kT}_{\mathrm{m}}}-\frac{\mathrm{E}}{\mathrm{kT}^{\prime}}\right) \mathrm{dT}^{\prime}\right] \\
\mathrm{I}^{\mathrm{GOK}}(\mathrm{T})=\mathrm{I}_{\mathrm{m}} \exp \left(\frac{\mathrm{E}}{\mathrm{kT}_{\mathrm{m}}}-\frac{\mathrm{E}}{\mathrm{kT}}\right)\left[1+\left(\frac{\mathrm{b}-1}{\mathrm{~b}}\right) \frac{\mathrm{E}}{\mathrm{kT}_{\mathrm{m}}} \int_{\mathrm{T}_{m}}^{\mathrm{T}} \exp \left(\frac{\mathrm{E}}{\mathrm{kT} \mathrm{T}_{\mathrm{m}}}-\frac{\mathrm{E}}{\mathrm{kT}^{\prime}}\right) \mathrm{dT}^{\prime}\right]^{-\frac{\mathrm{b}}{\mathrm{b}-1}}
\end{gathered}
$$

where $I$ and $I_{m}$ are $T L$ intensities for a given temperature $(T$, in $K)$ or at peak maximum $(\mathrm{Tm})$ and temperature linearly increases with time ( $\mathrm{t})$ from $\mathrm{T}_{0}$ to $\mathrm{T}, \mathrm{T}(\mathrm{t})=\mathrm{T}_{0}+\beta \mathrm{t}, \beta\left({ }^{\circ} \mathrm{C} / \mathrm{s}\right)$ is the linear heating rate; $\mathrm{E}(\mathrm{eV})$ is the trap activation energy; $\mathrm{k}\left(\mathrm{eV} \cdot \mathrm{K}^{-1}\right)$ is the Boltzmann constant; and $\mathrm{b}$ is the kinetic order parameter. In case of continuous energy distribution of traps present in material, usually exponential or gaussian functions are used, which can be described by Equations (7) and (8) [49-51]:

$$
\begin{gathered}
\mathrm{n}^{\operatorname{Exp}}(\mathrm{E})=\frac{\mathrm{n}_{0}}{\sigma} \exp \left(-\frac{\mathrm{E}-\mathrm{E}_{0}}{\sigma}\right) \\
\mathrm{n}^{\text {Gaus }}(\mathrm{E})=\frac{\mathrm{n}_{0}}{\sqrt{2 \pi \sigma^{2}}} \exp \left[-\frac{\left(\mathrm{E}-\mathrm{E}_{0}\right)^{2}}{2 \sigma^{2}}\right]
\end{gathered}
$$

where $n$ and no are number of trapping centres of a given energy (E) and total density of trapped charges $\left(\mathrm{cm}^{-3}\right), \mathrm{E}_{0}$ is either the shallowest energy in the distribution (exponential model) or the most populated trapping level (gaussian distribution), and $\sigma$ is the parameter related to the width of the distribution. Based on these distributions, two models are generally in use, describing dependencies of TL emission intensity vs. energy and temperature according to Equations (9) and (10):

$$
\begin{aligned}
\mathrm{I}^{\mathrm{Exp}}(\mathrm{T}) & =\int_{\mathrm{E}_{\mathrm{o}}}^{+\infty} \mathrm{s} \frac{\mathrm{n}_{0}}{\sigma} \exp \left(-\frac{\mathrm{E}-\mathrm{E}_{0}}{\sigma}\right) \exp \left(-\frac{\mathrm{E}}{\mathrm{kT}}\right) \exp \left[-\frac{\mathrm{s}}{\beta} \int_{\mathrm{T}_{o}}^{\mathrm{T}} \exp \left(-\frac{\mathrm{E}}{\mathrm{kT}^{\prime}}\right) \mathrm{dT}^{\prime}\right] \mathrm{dE} \\
\mathrm{I}^{\mathrm{Gaus}}(\mathrm{T}) & =\int_{-\infty}^{+\infty} \mathrm{s} \frac{\mathrm{n}_{0}}{\sqrt{2 \pi \sigma^{2}}} \exp \left(-\frac{\left(\mathrm{E}-\mathrm{E}_{0}\right)^{2}}{2 \sigma^{2}}\right) \exp \left(-\frac{\mathrm{E}}{\mathrm{kT}}\right) \exp \left[-\frac{\mathrm{s}}{\beta} \int_{\mathrm{T}_{o}}^{\mathrm{T}} \exp \left(-\frac{\mathrm{E}}{\mathrm{kT}^{\prime}}\right) \mathrm{dT}^{\prime}\right] \mathrm{dE}
\end{aligned}
$$

where $\mathrm{s}\left(\mathrm{s}^{-1}\right)$ is the frequency coefficient related to the type of defect and other symbols are as described above. The models described according to Equations (5)-(10) are implemented in a dedicated glow curve deconvolution software and are described in several papers $[49,50]$. The software was used for analysis of glow curves obtained during measurement of PPG sample, and graphical representation of the obtained results are presented in Figure 10.

The deconvolution procedure was performed in order to recognize the structure of the TL glow curve, structure, and types of defects present in the material and to estimate the energy levels of the trapping centers related to the particular TL emissions from the material. Verification of the proper localization of particular peaks was based on the consecutive analysis of the experimental data and results obtained from deconvolution analysis using the GCA (Glow Curve Analysis) software [50]. The selection between exponential and gaussian distributions for continuous type defects was made taking as a criterion the possibly lowest value of FOM (Figure of Merit) parameter, which indicates the difference between experimental data and computer-simulated glow curves based on the parameters obtained during deconvolution procedure. The commonly accepted values of FOM are usually below $5 \%$. The results obtained during deconvolution analysis of glow curves obtained from VHR measurements of PPG glass are presented in Table 5. 


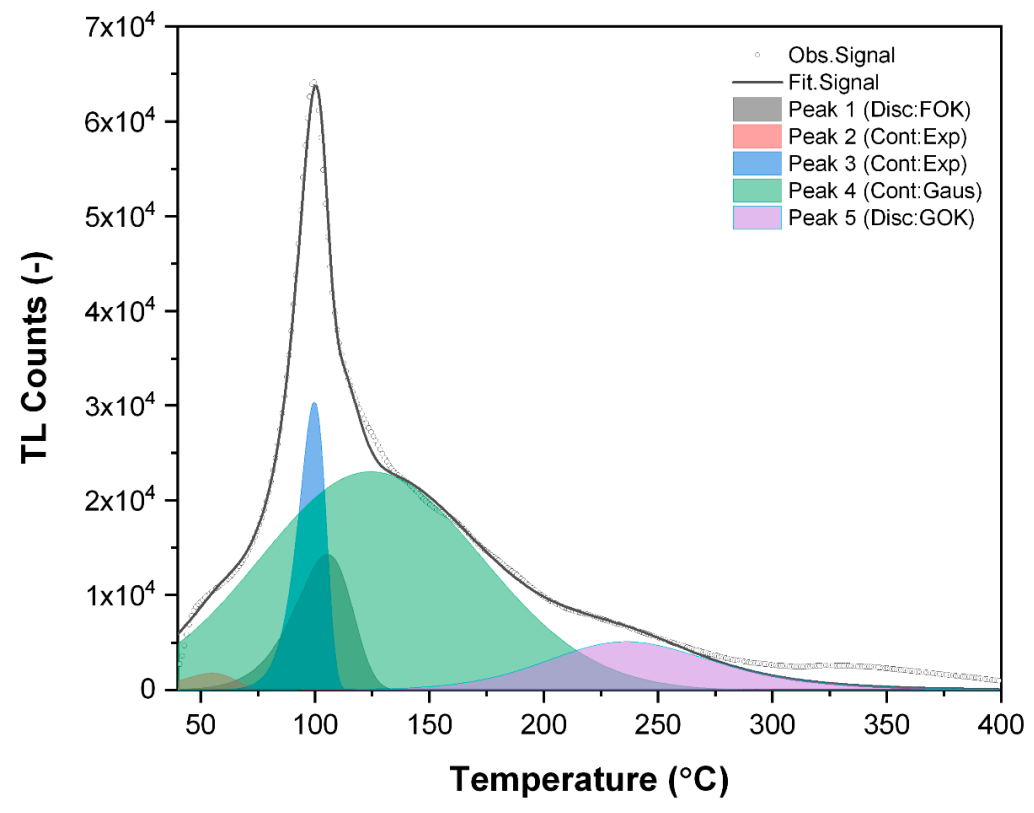

Figure 10. Results of deconvolution procedure of TL signal from PPG samples irradiated with 10 kGy radiation dose (electron accelerator, pulse duration $4 \mu \mathrm{s}$, heating rate $\beta=0.5^{\circ} \mathrm{C} / \mathrm{s}$ ).

Table 5. Fitting results and traps parameters obtained for PPG glass samples irradiated with radiation dose of ca. $10 \mathrm{kGy}$ and heating rates $(\beta)$ of $0.5,1.0$, and $2.0^{\circ} \mathrm{C} / \mathrm{s}$.

\begin{tabular}{cccccccc}
\hline Peak Type & $\boldsymbol{\beta}\left({ }^{\circ} \mathbf{C} / \mathbf{s}\right)$ & $\mathbf{E}(\mathbf{e V})$ & $\mathbf{T}_{\mathbf{m}}\left({ }^{\circ} \mathbf{C}\right)$ & $\mathbf{s}\left(\mathbf{s}^{-\mathbf{1}}\right)$ & $\boldsymbol{\sigma}(\mathbf{e V})$ & $\mathbf{b}$ & $\mathbf{F O M}$ \\
\hline Peak 1 (Disc:FOK) & & 0.79 & 54.9 & $5.05 \times 10^{10}$ & - & - \\
Peak 2 (Cont:Exp) & & 2.03 & 99.7 & $2.20 \times 10^{26}$ & 0.000 & - \\
Peak 3 (Cont:Exp) & 0.5 & 0.98 & 103.7 & $5.14 \times 10^{11}$ & 0.005 & - & $2.17 \%$ \\
Peak 4 (Cont:Gaus) & & 0.67 & 133.1 & $4.99 \times 10^{6}$ & 0.075 & - & 2.00 \\
Peak 5 (Disc:GOK) & & 0.83 & 235.9 & $3.12 \times 10^{6}$ & - & - \\
\hline Peak 1 (Disc:FOK) & & 0.79 & 60.9 & $5.93 \times 10^{10}$ & - & - \\
Peak 2 (Cont:Exp) & & 2.03 & 102.7 & $2.62 \times 10^{26}$ & 0.000 & - \\
Peak 3 (Cont:Exp) & 1 & 0.98 & 112.6 & $4.87 \times 10^{11}$ & 0.005 & - \\
Peak 4 (Cont:Gaus) & & 0.64 & 143.4 & $2.50 \times 10^{6}$ & 0.073 & - \\
Peak 5 (Disc:GOK) & & 0.8 & 260.8 & $1.12 \times 10^{6}$ & - & 2.00 \\
\hline Peak 1 (Disc:FOK) & & 0.79 & 70.8 & $5.06 \times 10^{10}$ & - & - \\
Peak 2 (Cont:Exp) & & 2.03 & 107.6 & $2.25 \times 10^{26}$ & 0.004 & - \\
Peak 3 (Cont:Exp) & 2 & 0.98 & 123.5 & $4.08 \times 10^{11}$ & 0.000 & - \\
Peak 4 (Cont:Gaus) & & 0.58 & 162 & $3.41 \times 10^{5}$ & 0.054 & - \\
Peak 5 (Disc:GOK) & & 0.86 & 270.7 & $6.73 \times 10^{6}$ & - & $2.99 \%$ \\
\hline
\end{tabular}

In Table 5, one presented only data obtained during deconvolution of TL emission curves for three lowest heating rates of $0.5,1.0$, and $2.0^{\circ} \mathrm{C} / \mathrm{s}$. The general conclusion from these results is that all sets of data correlate quite well each other for particular peaks. For Peak 2, one can find relatively high value of the frequency factor; however, this could be due to the exponential expression used to obtain this value and based on energy of the trapping center, so even small variation in E value may lead to large variation and uncertainty in calculated value of s. It was impossible to correlate all the data obtained from deconvolution procedure with the results from VHR measurements, especially for the higher heating rates above $2{ }^{\circ} \mathrm{C} / \mathrm{s}$. It was probably due to a limited thermal conductivity of the samples (ca. $40 \mathrm{mg}$ in weight, $5 \mathrm{~mm}$ in diameter, and ca. $1 \mathrm{~mm}$ thickness) and in consequence delayed response of the TL emission vs. temperature measured during samples reading. Nevertheless, the careful analysis of the available data allowed for determination of the positions of the peaks in TL emission curves for which temperature 
shifts were monitored in relation to the applied heating rate. Analysis was performed according to the known VHR based correlation of the TL peak position and heating rate, which can be described by Equation (11) [49]:

$$
\frac{\mathrm{E}}{\mathrm{kT}_{\mathrm{m}}^{2}}=\frac{\mathrm{s}}{\beta} \exp \left(-\frac{\mathrm{E}}{\mathrm{kT}_{\mathrm{m}}}\right)
$$

where all symbols are as described previously. Equation (11) can be easily linearized, and the obtained dependencies of $\ln \left(\mathrm{T}_{\mathrm{m}}^{2} / \beta\right)=\mathrm{f}(1 / \mathrm{T})$ for PPG glass samples are presented in Figure 11. As mentioned above, due to limited thermal conductivity of the samples, it was very difficult to correlate results obtained from the higher heating rates, for which calculated values of departed significantly from linearity. Such prepared data allowed for experimental verification of the values obtained during deconvolution procedure. For all presented dependencies, one can observe purely linear correlations, whose slopes allowed for experimental determination of the energies of trapping centers, presented in Table 6 together (for comparison) with those obtained from deconvolution procedure. In most cases, the presented values are fully convergent, with only higher discrepancy observed for Peak 3, in which case the value obtained from VHR method was ca. 15\% lower than that from deconvolution analysis.

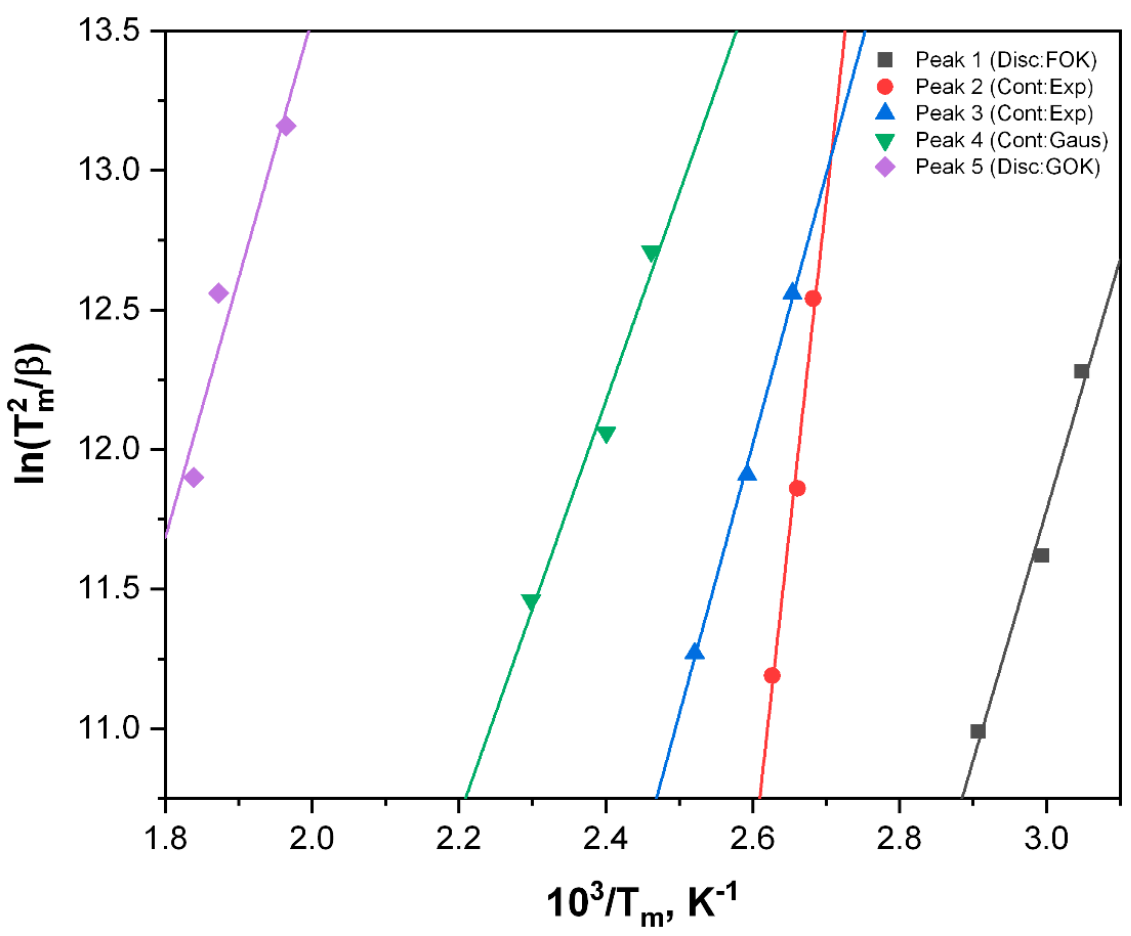

Figure 11. Results from VHR method obtained for PPG glass samples for three different heating rates of $0.5,1.0$, and $2.0^{\circ} \mathrm{C} / \mathrm{s}$.

Table 6. Comparison of energies of trapping centers present in PPG glass sample.

\begin{tabular}{ccc}
\hline \multirow{2}{*}{ Peak } & \multicolumn{2}{c}{$E \mathbf{( e V )}$} \\
\cline { 2 - 3 } & Deconvolution & VHR \\
\hline Peak 1 & 0.79 & $0.77 \pm 0.11$ \\
Peak 2 & 2.03 & $2.03 \pm 0.29$ \\
Peak 3 & 0.98 & $0.83 \pm 0.04$ \\
Peak 4 & 0.63 & $0.64 \pm 0.10$ \\
Peak 5 & 0.83 & $0.80 \pm 0.23$ \\
\hline
\end{tabular}


Taking into account the data from $\mathrm{T}_{\max }-\mathrm{T}_{\text {stop }}$ and VHR experiments, it seems that structure of the TL signals in terbium-doped phosphate glasses should exhibit similar behavior as observed in case of pure PPG glass. Because of a vast number of experiments required and calculation works to be performed, one decided that due to the complexity of the thermoluminescence signals from terbium-doped phosphate glasses, this topic deserves wider discussion and analysis in another separate publication, for which the results presented in this work provide a great introduction.

\subsection{Influence of Preheating before Readout on TL Signals and Signal Loss in Time}

3.4.1. Influence of Preheating before Readout on TL Signals

Because of the presence of large number of signals at lower temperatures, one can expect that the signal may be degraded during time due to the random recombinations and emission processes. After verification, this supposition was positively confirmed in experiment, whose results are shown further in Section 3.4.2.

Thus, we decided to check the effect of preheating detectors prior to readout and its influence on the obtained TL curves. The preheating and TL signal stability experiments were performed on the PPG_Tb30 samples. Glass detectors were preheated directly before readout. Two temperatures were used for preheating, namely, $120^{\circ} \mathrm{C}$ and $200{ }^{\circ} \mathrm{C}$. The results of these experiments are presented in Figure 12. From the data presented in Figure 8, it is evident that preheating erases part of the TL signal, which cannot be obtained again. In case of the not preheated sample PPG_Tb30, at first sight one can observe three main peaks, at ca. $120^{\circ} \mathrm{C}, 180^{\circ} \mathrm{C}$, and $260^{\circ} \mathrm{C}$. During preheating at $120^{\circ} \mathrm{C}$, two or even three low-temperature peaks, as presented in Figure $8 \mathrm{~b}$, are cleaned by emptying traps presented in the material. It is clear that removal of the lower temperature signals leads to situation, in which, after annealing, they do not contribute to the overall TL emission curve. Similarly, preheating to higher temperature of $200{ }^{\circ} \mathrm{C}$ consequently must lead to emptying of the five traps with lower energies existing in the material, as shown in Figure 8.

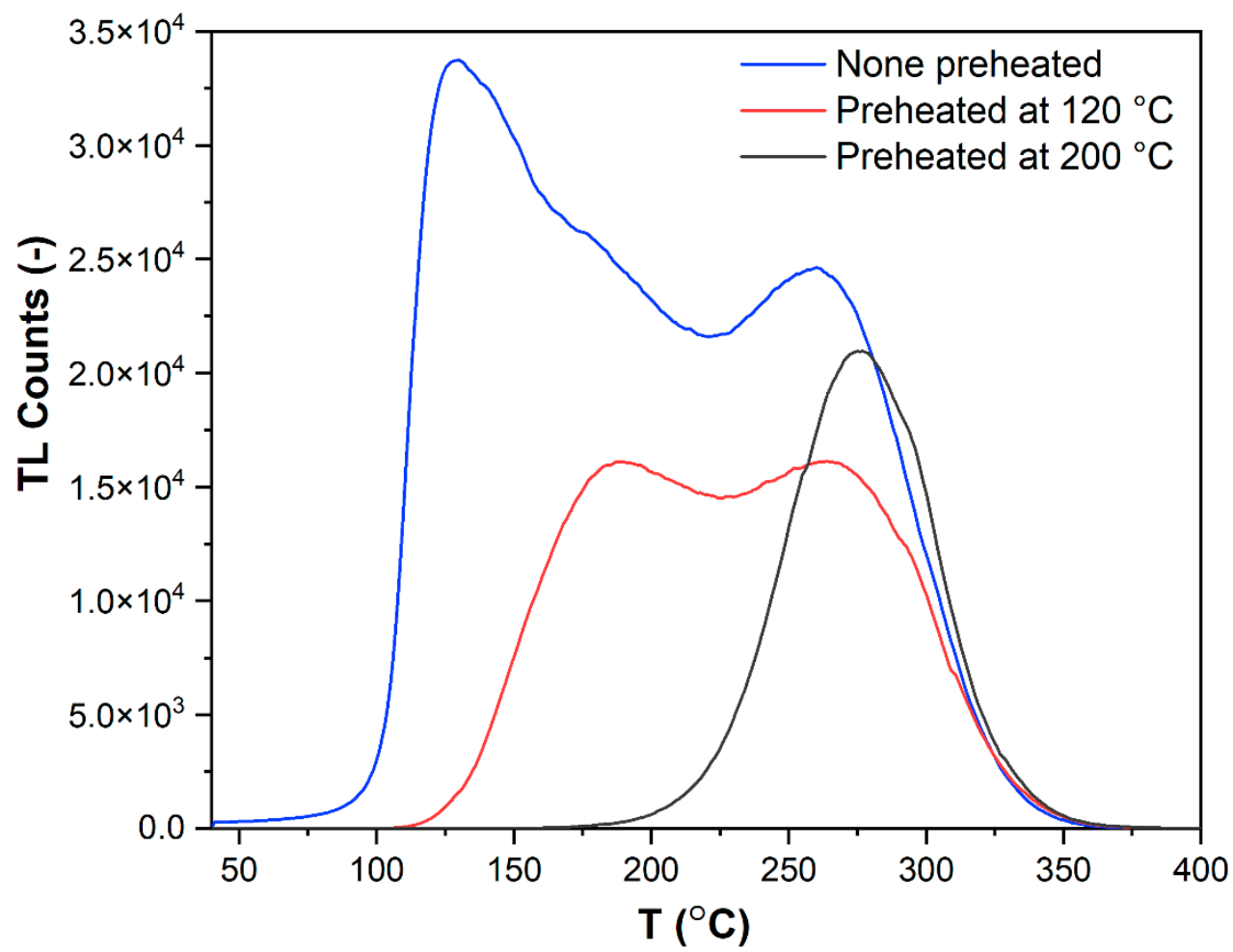

Figure 12. TL curves for PPG_Tb30 samples irradiated using beta radiation (4 $\mu$ s pulse duration), no preheating of detector, sample preheated at $120^{\circ} \mathrm{C}$, and at $200^{\circ} \mathrm{C}$; radiation dose applied ca. $30 \mathrm{kGy}$. 
The overall influence of the preheating procedure on the radiation dose and integrated TL intensity response is presented in Figure 13. Obviously, the TL signal integrals are more intensive for the non-preheated samples. This is a logical consequence of partial emptying of traps through preheating. Interestingly, preheating also has an influence on the dependencies of TL signal integrals vs. radiation dose absorbed. For the non-preheated samples, the dose response is of exponential character (saturation-type curve, triangles in Figure 13), for which signal saturation is observed above $15 \mathrm{kGy}$. For the sample preheated at $120^{\circ} \mathrm{C}$, the dose response is of linear character for lower dose range (up to $15 \mathrm{kGy}$ ), and for higher doses exhibits it exponential character (circles in Figure 13). Finally, after preheating at $200{ }^{\circ} \mathrm{C}$, the presented in Figure 13 data representing the dependence of TL signal integral vs. dose absorbed remain linear even for the highest dose up to ca. 30 kGy. For comparison purposes, in Figure 13 both exponential fittings as well as linear approximations are shown for a clear presentation of the observed differences and effects of samples preheating at different conditions. After this analysis it is clear that preheating efficiently erases part of the lower energy traps, that, as one can observe, affects significantly the linearity of the dependence of integrated TL signal vs. radiation dose. With increasing of the absorbed dose, the low temperature defects saturate more effectively in comparison with those corresponding to higher temperatures. In such case, high-energy defects play a major role in TL signal generation.

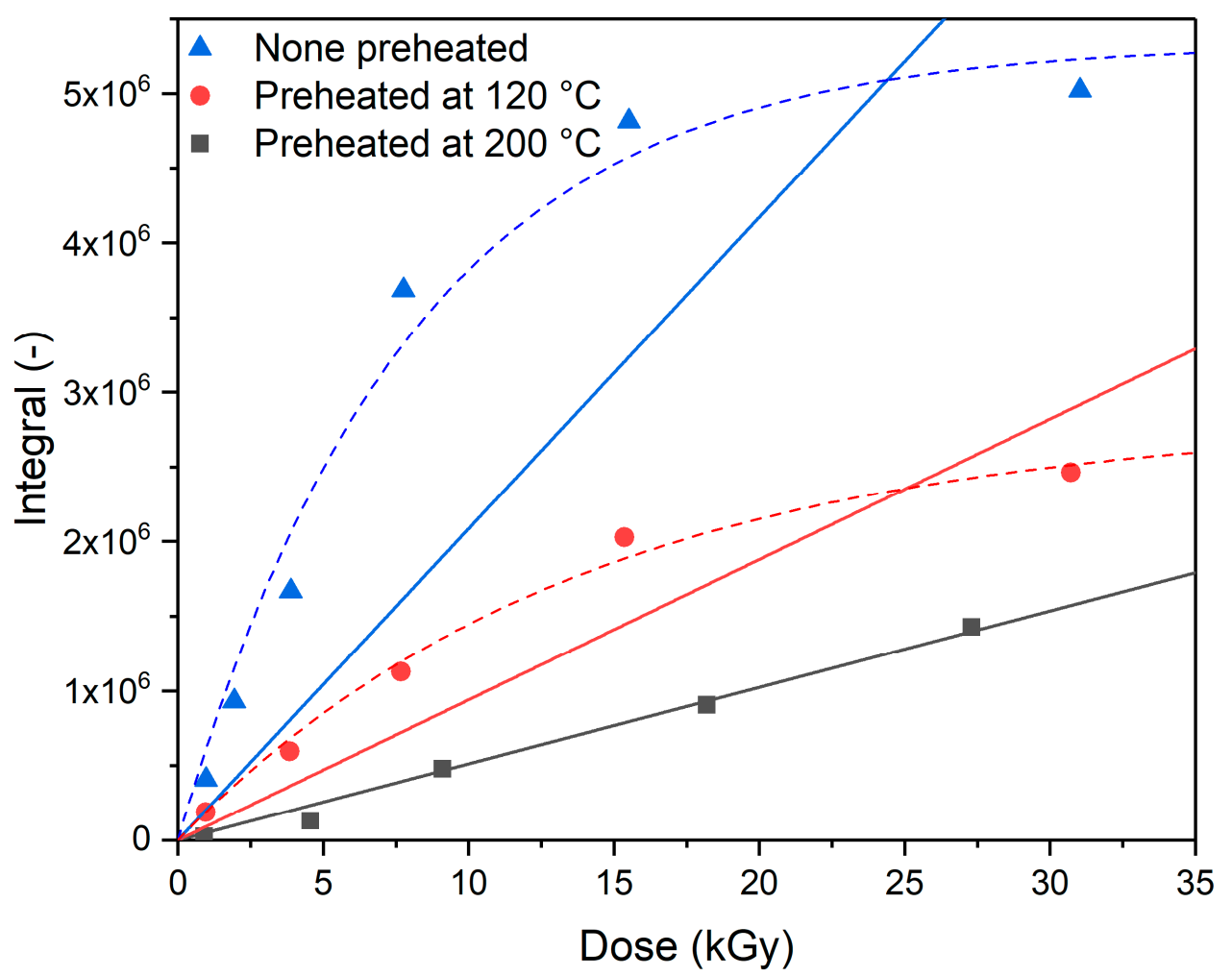

Figure 13. Dependencies of TL signal integral vs. dose absorbed for preheated PPG_Tb30 glass dosimeter irradiated with beta radiation (4 $\mu$ s pulse duration).

\subsubsection{Effect of Preheating on Signal Loss in Time}

Another important aspect in radiation dosimetry is the stability of signal generated upon irradiation within the detector used. To investigate the signal loss in time, samples of PPG_Tb30 were irradiated using LINAC with dose of $3.65 \mathrm{kGy}$. After irradiation, samples 
were stored in dark and preheated right before readout. To compare the obtained results in a quantitative way, Equation (12) was used:

$$
\mathrm{SL}=\frac{\mathrm{N}_{\text {int }}-\mathrm{N}_{\text {int }}\left(\mathrm{t}_{0}\right)}{\mathrm{N}_{\text {int }}\left(\mathrm{t}_{0}\right)} \cdot 100 \%
$$

where SL is the TL signal loss in time, in $\%$, and $\mathrm{N}_{\text {int }}$ and $\mathrm{N}_{\text {int(to) }}$ are the integrated TL signal intensities at a given time and just after irradiation.

As one can find from data presented in Figure 14, for the non-preheated samples, nearly $40 \%$ of the dosimetric signal is lost during first $24 \mathrm{~h}$ after irradiation. Finally, at the end of the monitored period of time, the signal loss after ca. $160 \mathrm{~h}$ (7 days) is roughly $63 \%$. For the samples preheated at $120^{\circ} \mathrm{C}$, one observes significant improvement, and the observed signal loss can be estimated for ca. $20-30 \%$ during first $160 \mathrm{~h}$. What is interesting, for the samples preheated at highest temperature $\left(200^{\circ} \mathrm{C}\right)$, the observed signal loss is the slightest and during $340 \mathrm{~h}$ (14 days) was found to be of ca. 19\%. Moreover, when analyzing the shape of signal loss vs. time dependency, one can find that it exhibits a purely linear character. This observation confirms that for the signal loss only recombination of the lower energy traps are responsible, after the emptying of which the main contributors to the TL signal are relatively stable traps activated at higher temperatures. Both, the dose-dependence of the signal and the decrease of the TL signal intensity over time indicate that the most optimal method of reading samples is their preheating at $200{ }^{\circ} \mathrm{C}$, which provides signal linearity for high doses and relative stability of the dosimetric signal over time. Additionally, in case of the readout method based on preheating at $200^{\circ} \mathrm{C}$, one can easily apply the time-related correction of the dose measurement.

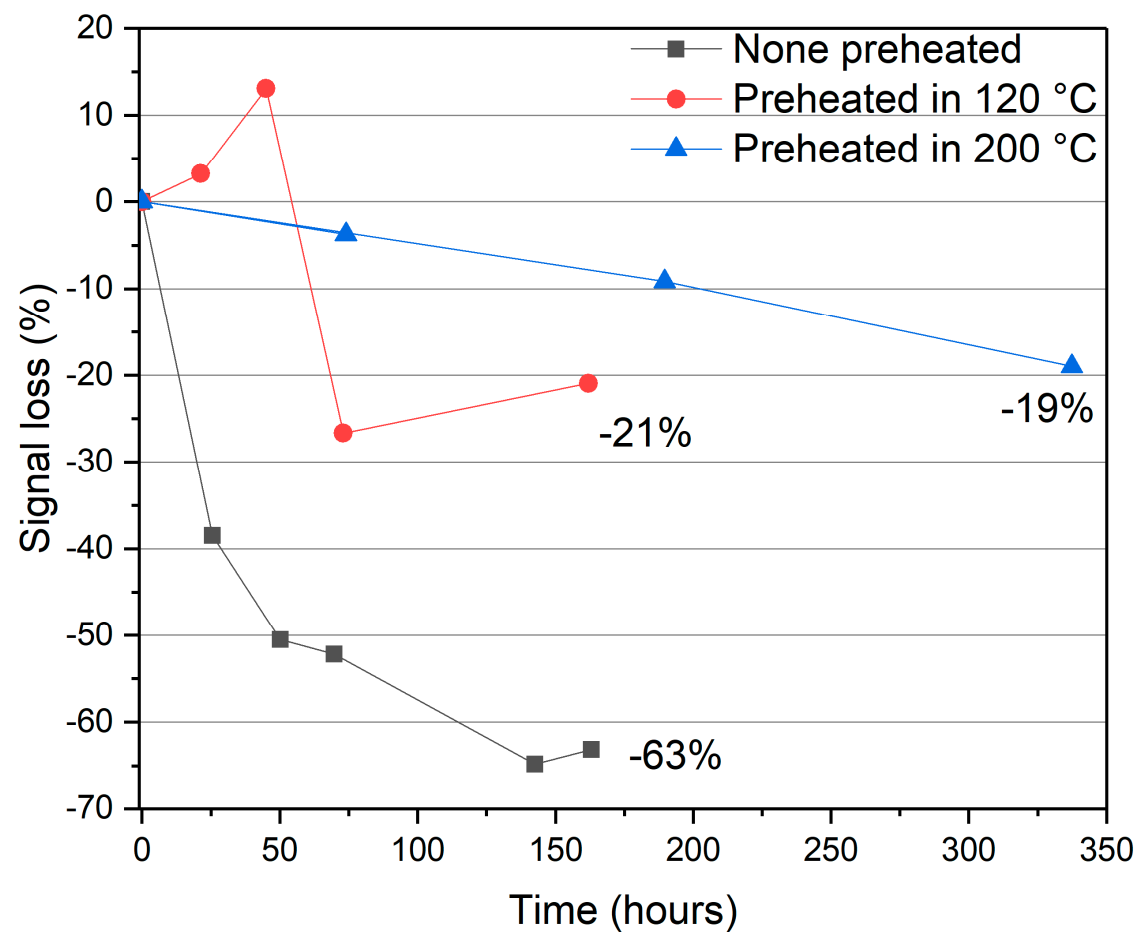

Figure 14. Dependencies of TL signal integral time after irradiation for preheated PPG_Tb30 glass

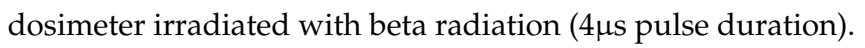

\section{Discussion}

The alumino-phosphate glasses doped with terbium with different amounts of REO (Rare Earth Oxide) were synthesized by melt-quench method. Glass powders were sieved and pelletized in the form of discs. Samples were irradiated using electron accelerator and irradiation chamber $(\gamma$ and $\beta$-) with radiation dose ranges up to $35 \mathrm{kGy}$. For samples 
containing terbium oxide, special shutter had to be used due too significantly higher lightemission efficiency. Addition of terbium oxide, even in amounts of only $0.1 \%$, improves TL intensity significantly. The observed effect is a concentration-dependent phenomenon, as introduction of higher amounts of terbium results in further increasing of thermoluminescence yield. During the performed research, one established that TL signals from irradiated native and terbium-doped phosphate glasses consist of a combination of different defect types such as first order kinetics (FOK), general order kinetics (GOK), and signals of continuous energy distribution of trapping centers. Verification of the proper localization of particular peaks was based on the consecutive analysis of the experimental data, and the results were obtained from deconvolution analysis using GCA (Glow Curve Analysis) software. Due to the extensive research related to the exact determination of signals deconvolution for glasses studied in this work, one may conclude that this is a very interesting topic that deserves further research and analysis. Additionally, it was found that simple preheating of dosimeters before readout influences dosimetric signals and signal loss and allows for optimization of the readout method of the investigated dosimeters, making the TL signal vs. radiation dose response more predictable. The performed research proved that preheating of the investigated samples at $200{ }^{\circ} \mathrm{C}$ improves the linearity of integral TL intensity vs. dose absorbed for doses higher than $15 \mathrm{kGy}$. Moreover, preheating allows one to minimize relative signal loss in samples over time. An additional advantage of the investigated dosimetric system is its ability to read dosimeters using a basic TL reader without any modifications. All obtained data suggest that the investigated material has high potential for use in high-dose ionizing radiation dosimetry.

Author Contributions: Conceptualization, A.G. and P.S.; methodology, A.G. and P.S.; software, P.S. and J.F.B.C.; validation, A.G., P.S. and J.F.B.C.; formal analysis, A.G. and P.S.; investigation, A.G. and P.S.; resources, A.G. and P.S.; data curation, A.G. and P.S.; writing-original draft preparation, A.G. and P.S.; writing-review and editing, A.G. and P.S. All authors have read and agreed to the published version of the manuscript.

Funding: Research financed by the statutory funding of Lodz University of Technology.

Conflicts of Interest: The authors declare no conflict of interest. The funders had no role in the design of the study; in the collection, analyses, or interpretation of data; in the writing of the manuscript; or in the decision to publish the results.

\section{References}

1. Sugawara, E.; Nikaido, H. Properties of AdeABC and AdeIJK Efflux Systems of Acinetobacter baumannii Compared with Those of the AcrAB-TolC System of Escherichia coli. Antimicrob. Agents Chemother. 2014, 58, 7250-7257. [CrossRef]

2. Nazarov, M.; Noh, D.Y. New Generation of Europium and Terbium Activated Phosphors: From Syntheses to Applications; CRC Press: Boca Raton, FL, USA, 2012; Available online: https:/ / www.crcpress.com/New-Generation-of-Europium--and-Terbium-ActivatedPhosphors-From-Syntheses/Nazarov-Noh/p/book/9789814310772 (accessed on 5 October 2019).

3. Ebendorff-Heidepriem, H.; Ehrt, D. Formation and UV absorption of cerium, europium and terbium ions in different valencies in glasses. Opt. Mater. 2000, 15, 7-25. [CrossRef]

4. Furmann, B.; Stefańska, D.; Chomski, M.; Suski, M.; Wilman, S. Hyperfine structure studies of the odd-parity electronic levels of the terbium atom. J. Quant. Spectrosc. Radiat. Transf. 2019, 237, 106613. [CrossRef]

5. Lu, C.-H.; Yang, C.-Y.; Som, S.; Das, S. Structural and luminescence characterization of terbium doped siliconitride phosphors for afterglow applications. Optik 2020, 203, 164030. [CrossRef]

6. Altunal, V.; Guckan, V.; Ozdemir, A.; Yegingil, Z. Radiation dosimeter utilizing optically stimulated luminescence of BeO: $\mathrm{Na}$, Tb, Gd ceramics. J. Alloy. Compd. 2020, 817, 152809. [CrossRef]

7. Guzmán-Olguín, J.; Guzmán-Mendoza, J.; Montalvo, T.R.; García-Hipólito, M.; Baéz-Rodríguez, A.; Falcony, C. Luminescent properties of terbium doped barium hafnate perovskite: Synthesis and characterization. J. Lumin. 2020, 226, 117459. [CrossRef]

8. Gingasu, D.; Mindru, I.; Ianculescu, A.; Preda, S.; Negrila, C.; Secu, M. Photoluminescence and thermoluminescence properties of the $\mathrm{Sr}_{3} \mathrm{Al}_{2} \mathrm{O}_{6}: \mathrm{Eu}^{3+} / \mathrm{Eu}^{2+}, \mathrm{Tb}^{3+}$ persistent phosphor. J. Lumin. 2019, 214, 116540. [CrossRef]

9. Bunzli, J.-C.; Wong, K.-L. Lanthanide mechanoluminescence. J. Rare Earths 2018, 36, 1-41. [CrossRef]

10. Sharipov, G.L.; Tukhbatullin, A.; Abdrakhmanov, A.M. Triboluminescence of crystals and suspensions of inorganic salts of lanthanides. Prot. Met. Phys. Chem. Surf. 2011, 47, 13-19. [CrossRef]

11. Zhao, Y.; Wang, Y.; Cui, M.; Jin, H.; Fan, Z.; Zhao, C.; Wu, X.; Townsend, P. Morphology and thermoluminescence properties of terbium doped magnesium orthosilicate. Radiat. Meas. 2017, 99, 44-49. [CrossRef] 
12. Prokić, M.; Yukihara, E. Dosimetric characteristics of high sensitive $\mathrm{Mg}_{2} \mathrm{SiO}_{4}$ : Tb solid TL detector. Radiat. Meas. 2008, 43, 463-466. [CrossRef]

13. Zhao, Y.; Wang, Y.; Jin, H.; Yin, L.; Wu, X.; Ma, Y.; Townsend, P.D. Thermoluminescence Spectra of Rare Earth Doped Magnesium Orthosilicate. J. Alloys Compd. 2019, 797, 1338-1347. [CrossRef]

14. Selvan, P.C.; Selvasekarapandian, S.; Neelamegam, P. Optical absorption, photoluminescence, and thermally stimulated luminescence of CsCl: Tb crystals. Phys. Status Solidi 1996, 194, 747-756. [CrossRef]

15. Lozano, I.; Roman-Lopez, J.; Valverde, M.; Garcia-Hipolito, M.; Díaz-Góngora, J.; Castañeda, J.G.; Alarcon-Flores, G. Thermoluminescence properties of cerium and terbium doped alpha-strontium pyrophosphate. Radiat. Meas. 2019, $129,106192$. [CrossRef]

16. Bangaru, S.; Muralidharan, G.; Brahmanandhan, G. Thermoluminescence and optical studies on X-irradiated terbium-doped potassium bromide crystals. J. Lumin. 2010, 130, 618-622. [CrossRef]

17. Azorin-Nieto, J.; Khaidukov, N.; Sánchez-Rodríguez, A.; Azorín-Vega, J. Thermoluminescence of terbium-doped double fluorides. Nucl. Instruments Methods Phys. Res. Sect. B Beam Interact. Mater. At. 2007, 263, 36-40. [CrossRef]

18. Andrade, M.; Azevedo, W.; Barros, V.; Khoury, H. Thermoluminescence of aluminum oxide co-doped with terbium and thulium obtained via combustion synthesis. Radiat. Meas. 2011, 46, 1474-1476. [CrossRef]

19. Zych, E.; Bolek, P.; Kulesza, D. On thermoluminescence of $\mathrm{Lu}_{2} \mathrm{O}_{3}$ : Tb, Ta ceramic storage phosphors. J. Lumin. 2017, 189, 153-158. [CrossRef]

20. Szajerski, P.; Jakubowska, M.; Gasiorowski, A.; Mandowska, E. Dosimetric properties of europium, gadolinium and cerium borosilicate glasses in application of electron beam dose measurements. J. Lumin. 2017, 182, 300-311. [CrossRef]

21. Saidu, A.; Wagiran, H.; Saeed, M.; Obayes, H.; Bala, A.; Usman, F. Thermoluminescence response of rare earth activated zinc lithium borate glass. Radiat. Phys. Chem. 2018, 144, 413-418. [CrossRef]

22. Prasad, S.; Reddy, M.S.; Kumar, V.R.; Veeraiah, N.; Nalluri, V. Specific features of photo and thermoluminescence of Tb ${ }^{3+}$ ions in $\mathrm{BaO}-\mathrm{M}_{2} \mathrm{O}_{3}(\mathrm{M}=\mathrm{Ga}, \mathrm{Al}, \mathrm{In})-\mathrm{P}_{2} \mathrm{O}_{5}$ glasses. J. Lumin. 2007, 127, 637-644. [CrossRef]

23. Ono, H.; Fujimoto, Y.; Yahaba, T.; Yanagida, T.; Koshimizu, M.; Asai, K. Thermoluminescence properties of $\mathrm{Tb}^{3+}-\mathrm{doped} \mathrm{CaO}-$ $\mathrm{Al}_{2} \mathrm{O}_{3}-\mathrm{B}_{2} \mathrm{O}_{3}$-based glasses. Opt. Mater. 2019, 87, 24-28. [CrossRef]

24. Roberts, C.J. Management and disposal of waste from sites contaminated by radioactivity. Radiat. Phys. Chem. 1998, 51, 579-587. [CrossRef]

25. Honma, T.; Sato, A.; Ito, N.; Togashi, T.; Shinozaki, K.; Komatsu, T. Crystallization behavior of sodium iron phosphate glass $\mathrm{Na} 2-\mathrm{Fe} 1+0.5 \mathrm{P}_{2} \mathrm{O}_{7}$ for sodium ion batteries. J. Non-Cryst. Solids 2014, 404, 26-31. [CrossRef]

26. Jha, P.K.; Pandey, O.; Singh, K. Non-isothermal crystallization kinetics of $\mathrm{K}_{2} \mathrm{O}$ modified sodium-phosphate glasses. J. Non-Cryst. Solids 2016, 440, 76-84. [CrossRef]

27. Gasiorowski, A.; Szajerski, P. Thermoluminescence characteristics and dose response of electron beam and gamma rays irradiated alumino-phosphate glasses doped with $\mathrm{Gd}_{2} \mathrm{O}_{3}$ and $\mathrm{Tb}_{2} \mathrm{O}_{3}$. J. Lumin. 2019, 214, 116519. [CrossRef]

28. Sharma, S.; De, M.; Jana, S. Terbium doped sodium phosphate glass: A strong green emitting glass. Optik 2018, 154, 576-580. [CrossRef]

29. Kuro, T.; Okada, G.; Kawaguchi, N.; Fujimoto, Y.; Masai, H.; Yanagida, T. Scintillation properties of rare-earth doped NaPO $3^{-}$ $\mathrm{Al}\left(\mathrm{PO}_{3}\right)_{3}$ glasses. Opt. Mater. 2016, 62, 561-568. [CrossRef]

30. Kawano, N.; Akatsuka, M.; Kimura, H.; Okada, G.; Kawaguchi, N.; Yanagida, T. Scintillation and TSL properties of Tb-doped $\mathrm{NaPO}_{3}-\mathrm{Al}\left(\mathrm{PO}_{3}\right)_{3}$ glasses. Radiat. Meas. 2018, 117, 52-56. [CrossRef]

31. Brahmachary, K.; Rajesh, D.; Balakrishna, A.; Ratnakaram, Y.C. Radiative Properties and Energy Transfer Mechanism of Sm ${ }^{3+}$ Ion in Zinc-Alumino-Sodium-Phosphate (ZANP) Glasses. Int. J. ChemTech Res. 2014, 6, 1705-1707.

32. Babkina, A.; Kulpina, E.; Sgibnev, Y.; Fedorov, Y.; Starobor, A.; Palashov, O.; Nikonorov, N.; Ignatiev, A.; Zyryanova, K.; Oreshkina, K.; et al. Terbium concentration effect on magneto-optical properties of ternary phosphate glass. Opt. Mater. 2020, 100, 109692. [CrossRef]

33. El Mesady, I.; Alawsh, S. Optical and luminescence properties of silicon doped alumino-phosphate-sodium glass system. J. Non-Cryst. Solids 2018, 482, 236-242. [CrossRef]

34. Brow, R.K.; Kirkpatrick, R.J.; Turner, G.L. Nature of Alumina in Phosphate Glass: II, Structure of Sodium Alurninophosphate Glass. J. Am. Ceram. Soc. 1993, 76, 919-928. [CrossRef]

35. Tricot, G.; Revel, B.; Wegner, S. Thermal stability of a low Tg phosphate glass investigated by DSC, XRD and solid state NMR. J. Non-Cryst. Solids 2011, 357, 2708-2712. [CrossRef]

36. Karabulut, M.; Metwalli, E.; Brow, R. Structure and properties of lanthanum-aluminum-phosphate glasses. J. Non-Cryst. Solids 2001, 283, 211-219. [CrossRef]

37. Stoch, L.; Stoch, P. Significance of crystallochemical factors in chemical reactions into the structure of solids. J. Therm. Anal. Calorim. 2012, 109, 763-766. [CrossRef]

38. Yang, R.; Wang, Y.; Chen, Y.; Hao, X.; Zhan, J.; Liu, S. Glass formation region of the lithium iron phosphate ternary system and the properties of obtained glasses. Ceram. Silikáty 2010, 54, 352-356.

39. Gasiorowski, A.; Szajerski, P. Particles size increase assisted enhancement of thermoluminescence emission in gadolinium and dysprosium oxide doped phosphate glasses. J. Alloy. Compd. 2020, 839, 155479. [CrossRef]

40. Thomas, S.; Chithambo, M. Thermoluminescence of K-Mg-Al-Zn fluorophosphate glass. Opt. Mater. 2017, 64, 302-309. [CrossRef] 
41. Jin, H.; Zhao, Y.; Wang, Y.; Xi, L.; Yin, L.; Ma, Y.; Townsend, P. Improved thermoluminescence response of terbium doped magnesium orthosilicate by co-doping with sodium ions. Opt. Mater. 2019, 98, 109448. [CrossRef]

42. Fukuda, Y. Thermoluminescence in calcium fluoride doped with terbium and gadolinium ions. Radiat. Meas. 2008, 43, 455-458. [CrossRef]

43. Abdel-Kader, A.; El-Mallawany, R.; Elkholy, M.; Farag, H. Thermoluminescence dosimetry of rare-earth doped tellurite phosphate glasses. Mater. Chem. Phys. 1994, 36, 365-370. [CrossRef]

44. Liu, L.; Zhang, Y.; Hao, J.; Li, C.; Tang, Q.; Zhang, C.; Su, Q. Thermoluminescence characteristics of terbium-doped $\mathrm{Ba}_{2} \mathrm{Ca}_{2}\left(\mathrm{BO}_{3}\right)_{2}$ phosphor. Phys. Status Solidi 2005, 202, 2800-2806. [CrossRef]

45. Kalnins, C.A.G.; Ebendorff-Heidepriem, H.; Spooner, N.A.; Monro, T.M. Enhanced radiation dosimetry of fluoride phosphate glass optical fibres by terbium (III) doping. Opt. Mater. Express 2016, 6, 3692-3703. [CrossRef]

46. Terbium Doped Glasses: Their Optical Properties and Potential Applications-Durham e-Theses, (n.d.). Available online: http:/ / etheses.dur.ac.uk/8176/ (accessed on 22 November 2020).

47. Wang, Y.; Jiang, Y.; Chu, X.; Xu, J.; Townsend, P.D. Thermoluminescence responses of terbium-doped magnesium orthosilicate with different synthesis conditions. Radiat. Prot. Dosim. 2013, 158, 373-377. [CrossRef] [PubMed]

48. McKeever, S.W.S. Thermoluminescence of Solids; Cambridge University Press (CUP): Cambridge, UK, 1985.

49. Benavente, J.; Gómez-Ros, J.; Correcher, V. Characterization of the thermoluminescence glow curve of $\mathrm{Li}_{2} \mathrm{~B}_{4} \mathrm{O}_{7}$ : Cu, Ag. Radiat. Meas. 2020, 137, 106427. [CrossRef]

50. Benavente, J.; Gómez-Ros, J.M.; Romero, A.M. Thermoluminescence glow curve deconvolution for discrete and continuous trap distributions. Appl. Radiat. Isot. 2019, 153, 108843. [CrossRef]

51. Gómez-Ros, J.M.; Correcher, V.; Garcia-Guinea, J.; Delgado, A. Evolution of the trapped charge distribution due to trap emptying processes in a natural aluminosilicate. Radiat. Prot. Dosim. 2006, 119, 93-97. [CrossRef] 